\begin{tabular}{|l|l|}
\hline $\begin{array}{l}\text { 2. To: (Receiving Organization) } \\
\text { Distribution }\end{array}$ & $\begin{array}{l}\text { 3. From: (Originating Organization) } \\
\text { Spent Nuclear Fuel Project }\end{array}$ \\
\hline $\begin{array}{l}\text { 5. Proj./Prog./Dept./Div.: } \\
\text { Spent Nuclear Fuel }\end{array}$ & $\begin{array}{l}\text { 6. Design Authority/Design Agent/Cog. Engr.: } \\
\text { R. Whit thurst R3-86 }\end{array}$ \\
\hline
\end{tabular}

\section{Originator Remarks:}

Initial Release

11. Receiver Remarks:

\begin{abstract}
4. Related EDT No.:
$\mathrm{N} / \mathrm{A}$

7. Purchase Order No.:

2445

9. Equip./Component No.:

CP 210, CP608
\end{abstract}

10. System/BIdg./Facility:

$142 \mathrm{~K}$

12. Major Assm. Dwg. No.:

$\mathrm{N} / \mathrm{A}$

13. Permit/Permit Application No.:

$\mathrm{N} / \mathrm{A}$

14. Required Response Date:

$7-2-99$

15.

DATA TRANSMITTED

\begin{tabular}{|l|l}
\hline $\begin{array}{c}\text { (A) } \\
\text { item } \\
\text { No. }\end{array}$ & (B) Document/Drawing No. \\
\hline 1 & SNE-3091 \\
\hline & \\
\hline & \\
\hline & \\
\hline & \\
\hline
\end{tabular}

16.

Approval Designator (F)

E, S, Q, D OR N/A

(See WHC-CM-3-5, Sec. 12.7)

1. Approval
2. Release
3. Information

17.

\begin{tabular}{|l|l|}
\hline $\begin{array}{l}\text { (C) Sheet } \\
\text { No. }\end{array}$ & $\begin{array}{c}\text { (D) Rev. } \\
\text { No. }\end{array}$ \\
\hline All & 0 \\
\hline
\end{tabular}

\begin{tabular}{|c|c|c|c|}
\hline$(F)$ & $(G)$ & $(H)$ & $(I)$ \\
\hline $\begin{array}{c}\text { Approval } \\
\text { nesig- } \\
\text { nator }\end{array}$ & $\begin{array}{c}\text { Reason Trans- } \\
\text { mittal }\end{array}$ & $\begin{array}{c}\text { Origi- } \\
\text { nator } \\
\text { Dispo- } \\
\text { stion }\end{array}$ & $\begin{array}{c}\text { Receiv- } \\
\text { er } \\
\text { Dispo- } \\
\text { sition }\end{array}$ \\
\hline
\end{tabular}

\begin{tabular}{|l|l|l|l|l} 
Cold Vacuum Drying Facilit & N/A & 1 & 1 & 1 \\
\hline
\end{tabular}

Safety Class Instrument \& Control System Design Description

\begin{tabular}{ll|l} 
& \\
\hline & \\
\hline & \\
\hline
\end{tabular}

KEY
Reason for Transmittal (G)

4. Review

5. Post-Review

6. Dist. (Receipt Acknow. Required)
Disposition (H) \& (I)

$\begin{array}{ll}\text { 1. Approved } & \text { 4. Reviewed no/comment } \\ \text { 2. Approved w/comment } & \text { 5. Reviewed w/comment } \\ \text { 3. Disapproved w/comment } & 6 \text {. Receipt acknowledged }\end{array}$
SIGNATURE/DISTRIBUTION

(See Approval Designator for required signatures)

\begin{tabular}{|c|c|c|c|c|c|c|c|c|c|c|}
\hline $\begin{array}{l}\text { (G) } \\
\text { Rea- } \\
\text { Son } \\
\end{array}$ & \begin{tabular}{|l}
$(\mathrm{H})$ \\
Disp.
\end{tabular} & \multicolumn{2}{|c|}{ (J) Name } & (K) Signature (L) (M) MSIN & $\begin{array}{l}\text { (G) } \\
\text { Rea- } \\
\text { son }\end{array}$ & $\begin{array}{l}(\mathrm{H}) \\
\text { Disp. }\end{array}$ & (J) Name & (K) Signature & (L) Date & (M) MSIN \\
\hline 1 & 1 & \multicolumn{3}{|c|}{ Design Authority R. Whitehurst (R3-8\&) $7 / 1 / 9 \mathrm{~g}$} & 3 & & \multicolumn{4}{|c|}{ B. Philipp (R3-86) } \\
\hline & & \multicolumn{3}{|c|}{ Design Agent } & 3 & & \multicolumn{4}{|c|}{ W. Alaconis (R3-86) } \\
\hline & & \multicolumn{3}{|c|}{ Cog. Eng. } & 3 & & \multicolumn{4}{|c|}{ C. Dickey (R3-86) } \\
\hline 1 & 1 & \multicolumn{3}{|c|}{ Cog.Mgr. C Haller (R3-11) C/Lalle } & 3 & & \multicolumn{4}{|c|}{ D. King (S1-53) } \\
\hline 3 & & \multicolumn{3}{|c|}{ QA S Mischke $(R 3-86)$} & 3 & & \multicolumn{4}{|c|}{ I. Schroeder $(S 2-45)$} \\
\hline 3 & & \multicolumn{3}{|c|}{ Safety J Brehm (R3-26) } & & & \multicolumn{4}{|c|}{ peaj: fex $\quad p_{3}-1$} \\
\hline & & \multicolumn{3}{|l|}{ Env. } & & & \multicolumn{4}{|c|}{80} \\
\hline \multicolumn{4}{|c|}{$\frac{\text { Signature of EDT }}{\text { Originator }}$} & T. Choho & \multicolumn{4}{|c|}{$\begin{array}{l}\text { C. Haller } \\
\substack{\text { Design Authority } \\
\text { Cognizant Manager }}\end{array}$} & OVAL (if re & $\begin{array}{l}\text { quired) } \\
\text { ments } \\
\text { ments }\end{array}$ \\
\hline
\end{tabular}




\title{
Cold Vacuum Drying Safety Class Instrumentation and Control System Design Description
}

\author{
R. Whitehurst \\ Fluor Daniel Hanford, \\ Richland, WA 99352 \\ U.S. Department of Energy Contract DE-AC06-96RL13200
}

EDT/ECN: EDT-625193

Org Code: $2 \mathrm{~F} 800$

B\&R Code: 39EW70400
UC: 510

CACN: 105568

COA: A000

Total Pages: 67

Key Words: SNF, CVD, W-441, design description, SCIC, Monitoring, Control, Safety

Abstract: .This document describes the Cold Vacuum Drying Facility (CVDF) Safety Class Instrumentation and Control system (SCIC). The SCIC provides safety functions and features to protect the environment, off-site and on-site personnel and equipment. The function of the SCIC is to provide automatic trip features, valve interlocks, alarms, indication and control for the cold vacuum drying process.

TRADEMARK DISCLAIMER. Reference herein to any specific commercial product, process, or service by trade name, trademark. manufacturer. or otherwise, does not necessarily constitute or imply its endorsement. recommendation, or favoring by the United States Government or any agency thereof or its contractors or subcontractors.

Printed in the United States of America. To obtain copies of this document, contact: Document Control Services, P.0. Box 950, Mailstop H6-08. Richland WA 99352. Phone (509) 372-2420; Fax (509) 376-4989.
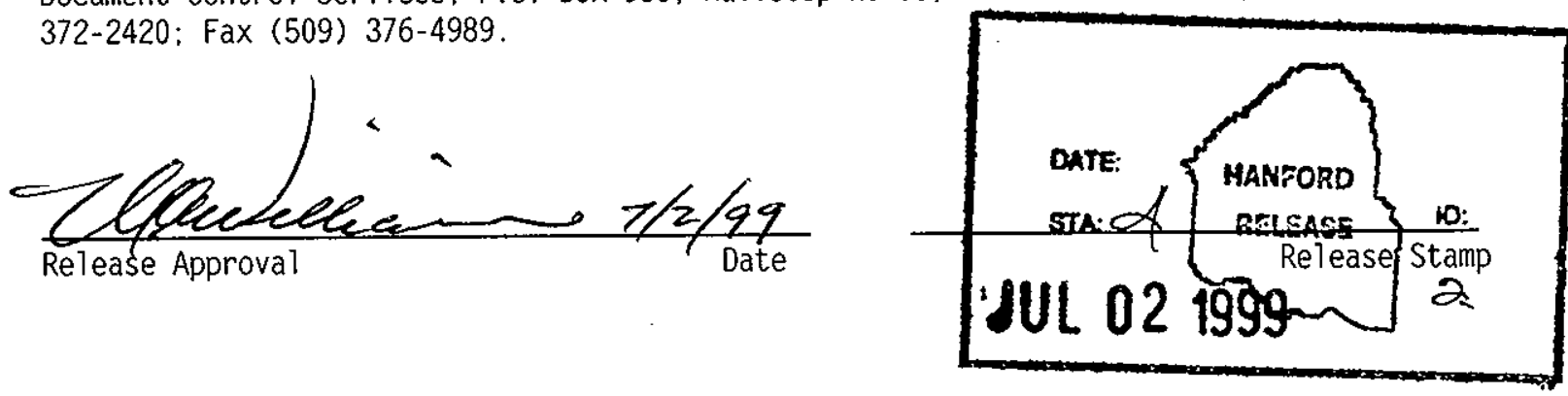

Approved for Public Release 
SNF-3091 REV 0

COLD VACUUM DRYING FACILITY

SAFETY-CLASS INSTRUMENTATION AND CONTROL SYSTEM

DESIGN DESCRIPTION

SYSTEM 93-2 


\section{TABLE OF CONTENTS}

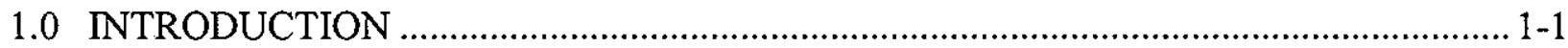

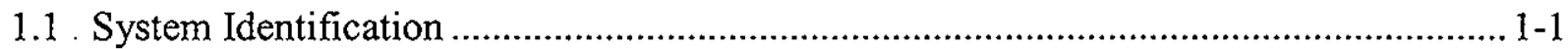

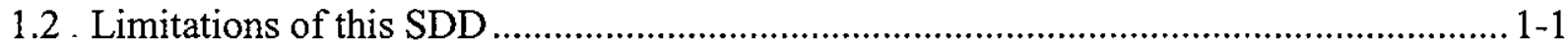

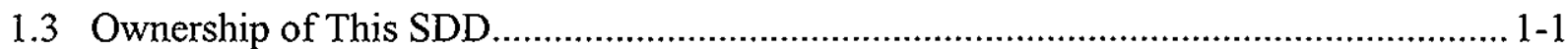

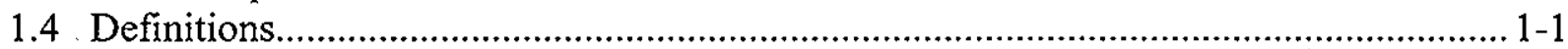

1.5 Acronyms

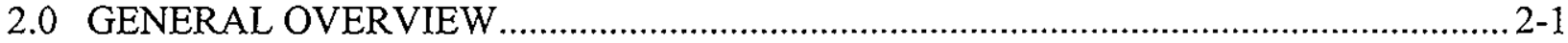

2.1 System Functions ..................................................................................................... 2-1

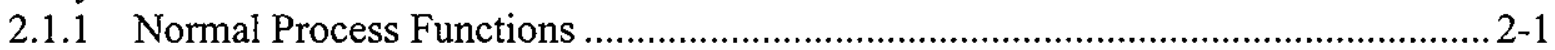

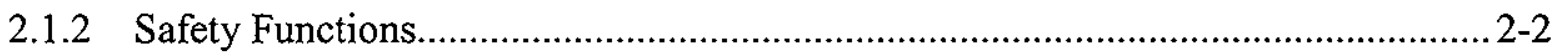

2.2 System Classification......................................................................................... 2-3

2.3 Basic Operational Overview ..................................................................................... 2-3

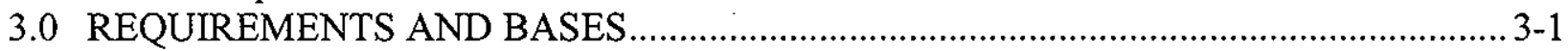

3.1 General Requirements......................................................................................... 3-1

3.1.1 Process Functional Requirements .................................................................... 3-1

3.1.2 Subsystem and Major Components ……......................................................... 3-11

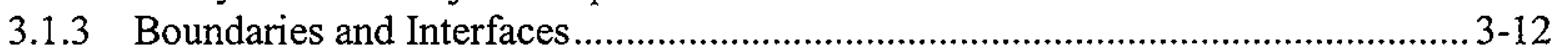

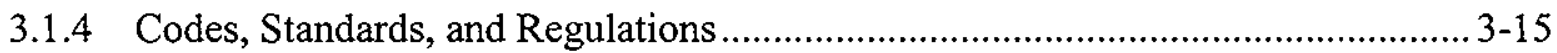

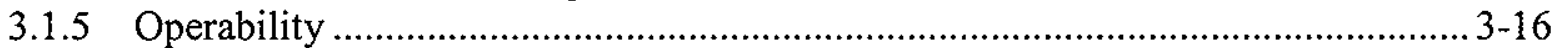

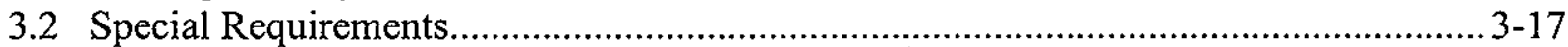

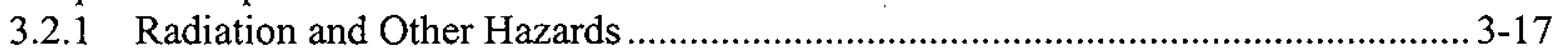

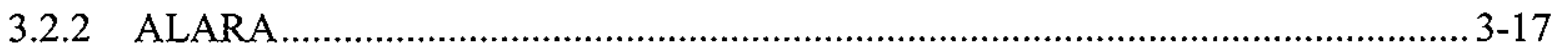

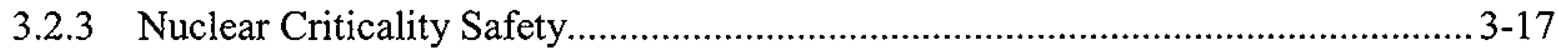

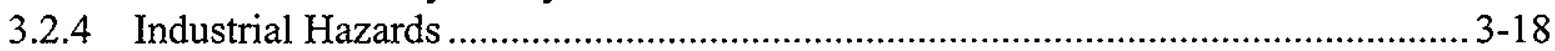

3.2.5 Operating Environment and Natural Phenomena ............................................ 3-18

3.2.6 Human Interface Requirements ................................................................... 3-19

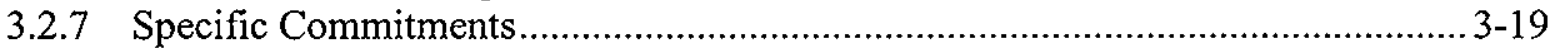

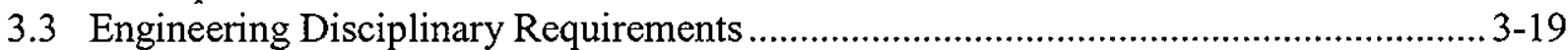

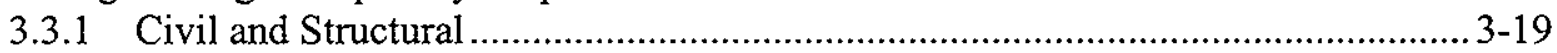

3.3.2 Mechanical and Materials .....................................................................................



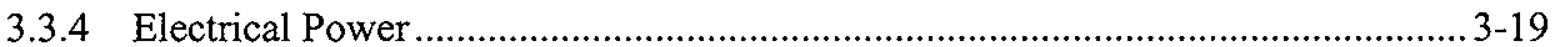

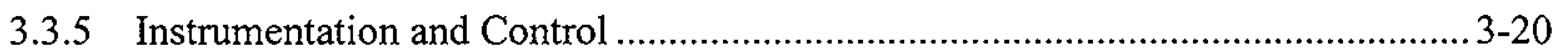

3.3.6 Computer Hardware and Software................................................................. 3-21

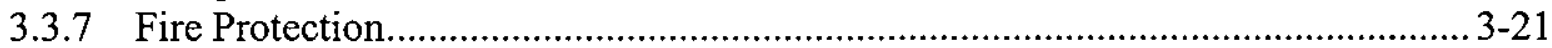

3.4 Testing And Maintenance Requirements................................................................. 3-21

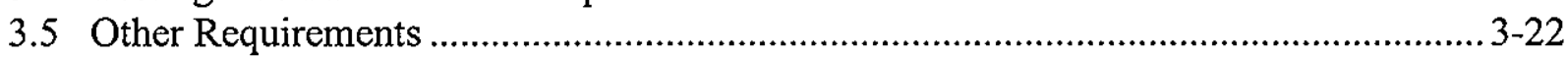

3.5.1 Security and Special Nuclear Material Protection ................................................ 3-23

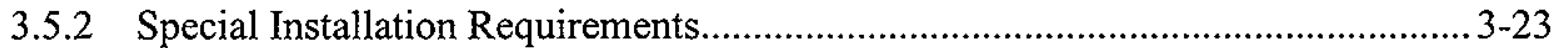

3.5.3 Reliability, Availability, and Preferred Failure Modes........................................... 3-23

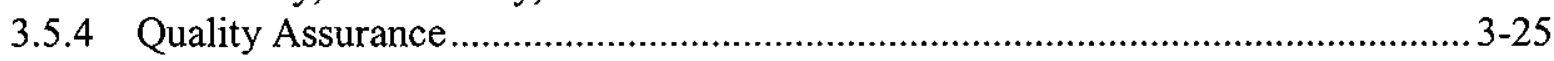

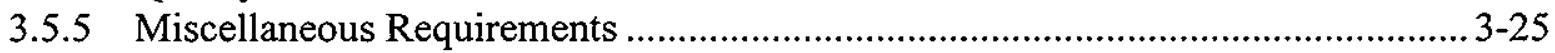




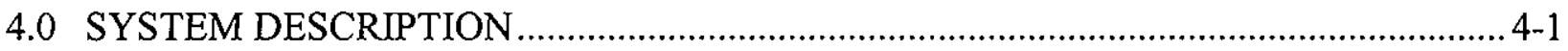

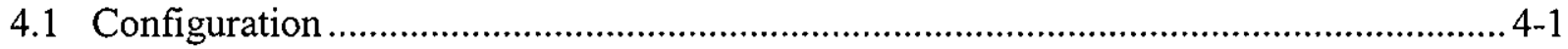

4.1.1 Description of System, Subsystems, and Major Components ................................ 4-1

4.1.2 Boundaries and Interfaces ............................................................................ 4-6

4.1.3. Physical Location and Layout.........................................................................

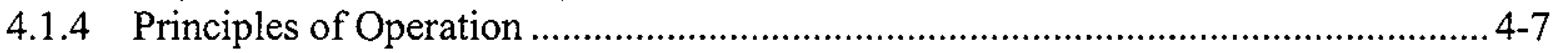

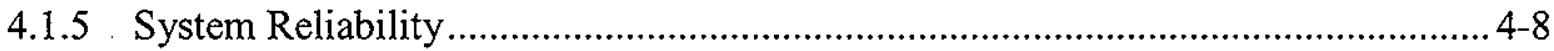

4.1.6 System Control Features ................................................................................... 4-8

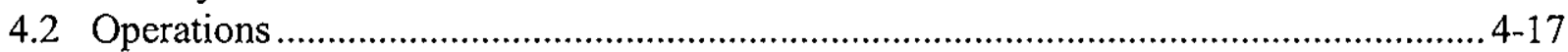

4.2.1 Initial Configurations (Pre-startup) ................................................................. 4-17

4.2.2 System Startup ............................................................................................ 4-17

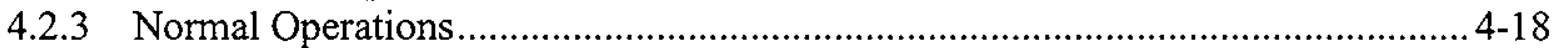

4.2.4 Off-Normal Operations ................................................................................ 4-18

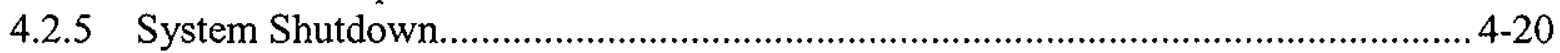

4.2.6 Safety Management Programs and Administrative Controls................................. 4-20

4.3 Testing And Maintenance ....................................................................................... 4-21

4.3.1 Temporary Configurations ........................................................................... 4-21

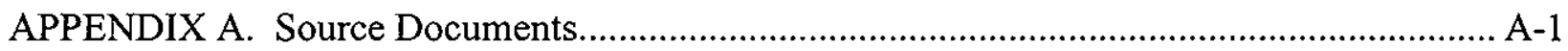

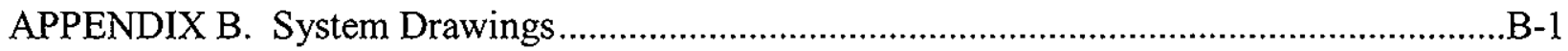

APPENDIX C. System Procedures......................................................................................... 


\section{LIST OF TABLES}

Table 3-1. Operating Environmental Limits....................................................................... 3-18

Table 4-1. Sensor Inputs for the TW Trip......................................................................... 4-3

Table 4-2. SCIC Trip Setpoints, Instrument Error, and Delay Times (2 Sheets) ..................... 4-10

Table 4-3. Safety-Class Instrumentation and Control Trip, Interlock, and Alarm Summary... 4-19

Table 4-3. Equivalent Parts Quality Assurance Requirements................................................ 4-21

\section{LIST OF FIGURES}

Figure 1-1. Safety Class Instrumentation and Control Diagram.............................................. 1-3

Figure 2-1. SCIC PLC Trip Logic ................................................................................ 2-5

Figure 2-2. SCIC PLC Trip Logic - Detail............................................................................. 2-6

Figure 3-1. Cold Vacuum Drying Process Connections and Instrument Basics ...................... 3-14 


\subsection{INTRODUCTION}

\subsection{System Identification}

This system design description (SDD) describes the Safety-Class Instrumentation and Control (SCIC) system (System 93-2) used by the Cold Vacuum Drying Facility (CVDF) process. It describes the primary purpose and design of the SCIC system, including the associated isolation valves, transmitters, and switches that interface with the SCIC system; and addresses the various requirements, such as the SCIC system safety functions, system operations, and system maintenance. See Figure 1-1 for the SCIC system layout.

\subsection{Limitations of this SDD}

This system design document is developed in accordance with the following documents and noted revisions:

- $\quad$ Project design requirements (HNF-SD-SNF-DRD-002)

- $\quad$ Master equipment list (SNF- 4148)

- Data and calculation matrix tracking list (SNF-3001)

- $\quad$ Sequence of operations (see HNF-2356)

- $\quad$ Final Safety Analysis Report (HNF3553, Annex B, Rev. 0)

- Technical Safety Requirements (HNF-3673)

- $\quad$ Safety Equipment List (HNF-SD-SNF-SEL-002)

Although this SDD mentions equipment that interfaces with the SCIC system, such as the Safety-Class Helium (SCHe) system (System 13-2) isolation valves, it does not address the balance of these systems. Important interface components are referenced to provide an understanding of the safety function, but interface systems and components are not fully discussed. Refer to the specific SDD of the applicable system, as appropriate.

\subsection{Ownership of This SDD}

The cold vacuum drying (CVD) Design Authority assigned to the SCIC system is responsible for the accuracy and technical content of this SDD. Any questions on the system or content of this document shall be resolved through the design authority.

\subsection{Definitions}

ANNULUS LOW LEVEL: This alarm signifies a low level in either of the redundant cask annulus inlet or outlet pipes.

ISO \& PURGE TRIP: This action is a result of contacts opening in the SCIC to de-energize the eight Multi-Canister Overpack (MCO) isolation valves and four Safety-Class Helium (SCHe) isolation valves. Since the eight valves are fail-closed, the $\mathrm{MCO}$ is isolated from the nonqualified portion of the process systems, the Vacuum Purge System (VPS) (System 07), the General Service Helium (GSHe) system (System 13-1) and the Process Water Conditioning 
(PWC) system (System 46). The SCHe purge is enabled when the SCHe valves are de-energized open (fail open on loss of power). This opens two valves on the long dip tube process connector and two on the short dip tube side.

PWC LOW FLOW: This alarm signifies that, during the PWC Pre-purge or Post-purge, either there was a low-flow rate or the minimum time for the purge was not met. Note: This alarm is designated as Defense-In-Depth, which is not a credited safety function.

PWC SEISMIC TRIP: A seismic trip will de-energize the two PWC pumps to preclude a spray leak that would cause a release of contaminated material. NOTE: This trip is designated as Defense-In-Depth, which is not a credited safety function.

TW TRIP: This event is a result of contacts opening in the SCIC to de-energize the Tempered Water (TW) heater starter and TW recirculation pump starter. This caused the 480VAC to be removed, thus de-energizing the heater and pump.

\subsection{Acronyms}

$\begin{array}{ll}\text { CSDD } & \text { Computer Software Design Description } \\ \text { CSRS } & \text { Computers Software Requirements Specification } \\ \text { CSUD } & \text { Computer Software User Document } \\ \text { CTC } & \text { Calibration and Test Computer } \\ \text { CVD } & \text { Cold Vacuum Drying } \\ \text { CVDF } & \text { Cold Vacuum Drying Facility } \\ \text { DBE } & \text { Design Basis Earthquake } \\ \text { IEEE } & \text { Institute of Electrical and Electronics Engineers } \\ \text { LSL } & \text { Level Switch Low } \\ \text { MCO } & \text { Multi-Canister Overpack } \\ \text { MCS } & \text { Monitoring and Control System } \\ \text { NEMA } & \text { National Electrical Manufacturers Association } \\ \text { NFPA } & \text { National Fire Protection Association } \\ \text { NRC } & \text { U.S. Nuclear Regulatory Commission } \\ \text { PLC } & \text { Programmable Logic Controller } \\ \text { QA } & \text { Quality Assurance } \\ \text { SCHe } & \text { Safety-Class Helium (system) } \\ \text { SCIC } & \text { Safety-Class Instrumentation \& Control (system) } \\ \text { SS } & \text { Safety-Significant } \\ \text { TSH } & \text { Temperature Switch High } \\ \text { TSHH } & \text { Temperature Switch High High } \\ \text { TW } & \text { Tempered Water (system) } \\ \text { UPS } & \text { Uninterruptible Power Supply } \\ \text { VPS } & \text { Vacuum Purge System }\end{array}$


Figure 1-1. Safety Class Instrumentation and Control Diagram

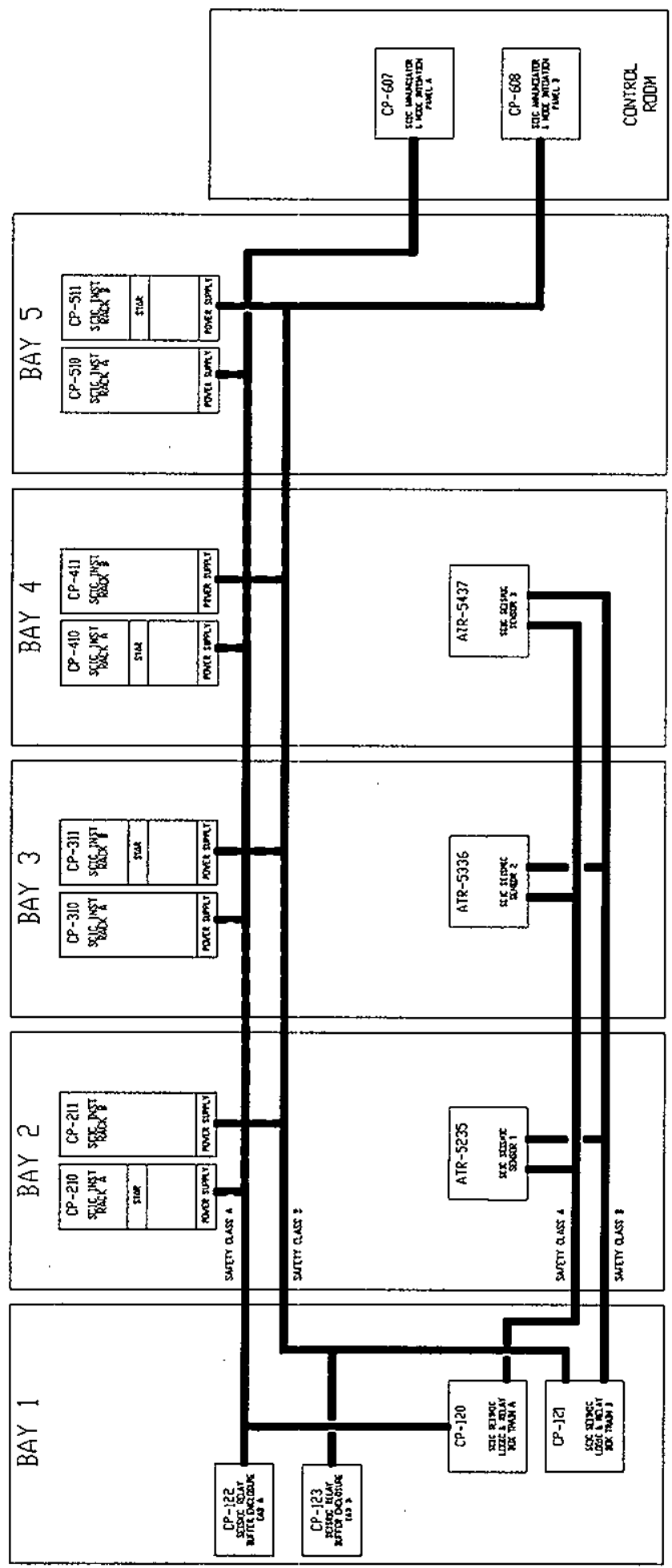




\subsection{GENERAL OVERVIEW}

This section provides a general overview of the SCIC system. Section 2.1 describes the system functions and discusses the system's safety functions. Section 2.2 states the SCIC system classification and Section 2.3 outlines the basic operation of the SCIC system.

\subsection{System Functions}

The SCIC system provides safety sensing, actuation logic, actuation signals, and control interfaces to prevent a MCO fuel runaway reaction (over temperature and pressure blowdown) or a hydrogen explosion within the MCO. Additional Defense-In-Depth features provide protection from both external hydrogen explosion and spray leak accidents.

The SCIC system provides active detection and response to process anomalies that, if unmitigated, could result in unacceptable consequences. To perform these functions, the SCIC system monitors process parameters, detects off-normal conditions, and actuates relays to deenergize the MCO isolation valves, the SCHe isolation valves, and the TW heater and pumps. See Figure 2-1 and 2-2 for general definitions of the trip logic.

The SCIC system is a fully automatic system that requires no operator action to detect and respond to process upsets within the process parameters that the SCIC controls. However, during processing, control room operators periodically reposition SCIC mode selector switches to provide appropriate SCIC coverage for the specific processing activity. The SCIC system consists of three portions: isolation and purge, TW over-temperature control, and the seismic system, which provides signals to both of the previous portions and the PWC pump trips. The SCIC does not provide automatic protection for those items requiring operation action, such as low TW annulus water level, ISO \& PURGE trip alarm helium bottle maintenance, and the PWC purge fail.

The SCIC system provides safety-class alarms to the CVDF control room for those events that require operator actions, including MCO isolation and purge (ISO \& PURGE) and ANNULUS LOW LEVEL.

The SCIC system also provides Defense-In-Depth features, including de-energizing the PWC recirculation pumps in a seismic event and providing an alarm in the CVDF control room for PWC low purge flow.

The SCIC system includes all of the equipment, actuation logic, electrical cabinets, conduits and wiring, local status indication and remote alarms, and controls for system operation and testing.

\subsubsection{Normal Process Functions}

During the Purge/Rinse mode, the SCIC opens the two SCHE long dip tube isolation valves to blow down any collected water in the line. Aside from this function, the SCIC is passive and responds when process parameters reach SCIC trip or alarm setpoints. The only operator functions required during normal operations is to control the position of the mode selector 
switches, test the annunciator function, and bypass the annulus water level alarm when required.

The SCIC system provides non-safety-class signals to the facility MCS and the PWC seismic pump shutdown starters. During normal process operations, the SCIC system allows signals from the facility control system to operate all of the isolation valves except the SCHe system valves. These signals and their wiring and conduit do not fall within the system boundary.

\subsubsection{Safety Functions}

The overall safety function of the SCIC system is to protect the MCO from hazardous conditions during process upsets. The SCIC system responds to key abnormal process parameters by providing signals to activate various trips, depending on the MODE. These responses are intended to cause actions that will prevent or mitigate a wide range of potential accidents, including MCO overpressurization, thermal runaway reaction, and internal hydrogen explosion accidents. Liquid release protection is classified as Defense-In-Depth.

The SCIC system is designated safety-class because of its role in preventing the occurrence of the MCO thermal runaway and MCO overpressurization accidents, which, unmitigated, would exceed offsite release limits. The SCIC system also plays a role in preventing the internal hydrogen explosion accident, which has unmitigated consequences that exceed onsite risk acceptance guidelines but do not exceed offsite release limits. The SCIC system performs a safety-significant function for prevention of this accident.

The SCIC system performs the following safety functions.

- MCO overpressurization accident - Process parameter upset characteristics of an MCO overpressurization are detected by the SCIC system, which responds by isolating the $\mathrm{MCO}$ from the process systems and actuating the $\mathrm{SCHe}$ system, which vents the MCO. A seismic event and/or a high process bay temperature initiates an SCIC system trip that isolates the $\mathrm{MCO}$ and activates the $\mathrm{SCHe}$ system, thereby pressurizing and purging the MCO. The TW heater will be de-energized by the SCIC system annulus water high temperature trip. The SCIC system alarms in the control room on detection of a low annulus water level and initiates operator response.

- Thermal runaway reaction - The SCIC system responds to process parameter upsets (i.e., high annulus water inlet temperature, exceeding time under vacuum, and low annulus water level) that are indicative of upset conditions that may lead to a thermal runaway accident. For some process upsets, the SCIC system provides signals to isolate and purge the MCO. The seismic trip or high temperature trip will also initiate an Isolation and Purge. The high annulus water temperature trip will de-energize the TW heater and pump. The SCIC system alarms on a low annulus water level in the control room, which requires operator action in the bay to stop the leak and to restore water to the annulus.

- Internal hydrogen explosion - The SCIC system responds to process parameter upsets that could allow the accumulation of excessive hydrogen inside the MCO or a line break that would allow the ingress of air. If selected process parameters are found to be outside 
limits, the SCIC system actuates the SCHe system, which is designed to maintain the hydrogen and oxygen concentration inside the MCO below the lower flammability limit. The SCIC system also detects high process bay temperatures and seismic events that could impair the system and responds by isolating the $\mathrm{MCO}$ and activating the $\mathrm{SCHe}$ system. A high water temperature in the TW (annulus) system results in shutting off power to the TW (annulus) system heater and circulation pump. The TW (annulus) low water level is monitored to sound an alarm for operator response.

- MCO external hydrogen explosion. The SCIC system responds to process parameter upsets and provides alarms to the CVDF control room if the PWC Pre-Purge or PostPurge fails. Activation of these alarms requires operator action to prevent the potential for an explosion in the PWC receiving tanks. This protection has been classified as Defense-In-Depth because the consequences of such an explosion do not exceed off-site or on-site guidelines. All components involved in this alarm are designated safety-class to provide for a simpler design, i.e. preclude mixing non-safety and safety class inside the SCIC panels.

- Liquid release. If a seismic event occurs, the SCIC system seismic detection system provides a Defense-In-Depth trip that shuts down power to the PWC system recirculation pumps.

\subsection{System Classification}

The SCIC system is a dedicated safety-class system whose function is to aid in the prevention of the thermal runaway, $\mathrm{MCO}$ overpressurization, and $\mathrm{MCO}$ internal explosion events by responding to abnormal conditions and actuating one or more safety-class systems or alarms. The SCIC system performs a safety-significant function for prevention of internal hydrogen explosions which have unmitigated consequences that exceed onsite guidelines but do not exceed offsite guidelines. The SCIC system meets the requirements of seismic Performance Category (PC) 3 using DOE-STD-1020-94, Natural Phenomena Hazards Design and Evaluation Criteria for Department of Energy Facilities.

All portions of the SCIC panels and starters were designed, fabricated, and tested to safety-class requirements. This approach was based on the risk involved in lesser events being reclassified and the minimal cost of maintaining safety-class qualifications. This approach also evaluated the complexity of providing physical and electrical separation between these similar features within the SCIC equipment. The PWC Pre-purge and Post-Purge alarms provide Defense-In-Depth prevention measures. The PWC recalculating pump seismic trip circuit is general service except the starters and starter mounting which is safety class.

\subsection{Basic Operational Overview}

The SCIC system monitors CVD process parameters, seismic conditions, and process bay temperatures. The system responds to anomalies that, if unmitigated, could result in an accident condition or undesirable process/facility off-normal event. 
The SCIC system and related safety-class systems must be operational before the Cask/MCO is connected to the process system and must remain operational for the duration of the drying process. The SCIC systems are tied to key process parameter sensors, which when taken as a whole, provide comprehensive and complete detection and response to the upset conditions. The systems are also designed such that they are redundant and fail-safe and that internal system failures actuate the safety structures, systems, and components (SSCs) to which they are connected. This automatic actuation upon failure ensures that loss of monitoring of a key parameter does not degrade the safety function of the SCIC system.

Actuation of the SCIC system includes the closure of isolation valves from the MCO to the process systems, and the opening of the $\mathrm{SCHe}$ system isolation valves to provide $\mathrm{MCO}$ purging and pressurization. A separate portion of the SCIC system also detects and actuates to stop excessive heat input to the MCO from high TW (annulus) MCO inlet temperature. This removes the power for the water heater and recirculating pump.

Alarms are provided to the CVDF control room for low water level in the Cask/MCO annulus activation of the SCIC MCO isolation and SCHe system purge (ISO\&PURGE), and PWC Purge failures.

The SCIC system responds to signals from the seismic sensors and auctioneering circuits. This response is intended to cause actions that prevent a MCO internal explosion and thermal runaway bounding accidents.

The SCIC system also provides non-safety-class signals to the facility Monitoring and Control System (MCS) for normal control, indication, and alarms and the PWC recirculating pump starters. The signals from the SCIC include all analog signals (flow and pressure), SCIC internal logic trip, alarm contact status and seismic trip contacts. All signals from the SCIC system are buffered to the MCS and PWC starters to provide isolation between safety and non-safety systems. Under normal conditions, the MCS controls all eight MCO isolation valves, though certain valves, such as the drain valves, are interlocked closed by the SCIC system during certain process modes. The SCHe valves are directly controlled by the SCIC and not the MCS. The TW heater and pump are normally controlled by the MCS through a separate starter box, power then is routed through the Train A, then Train B starters. Unless a fault condition (high temperature) occurs, these SCIC starters remain closed allowing normal MCS control. During an SCIC trip condition, both Train A and B starters open causing a loss of power to the heater and pump. 


\section{Figure 2-1. SCIC PLC Trip Logic}

\section{SCIC PLC TRIP LOGIC}

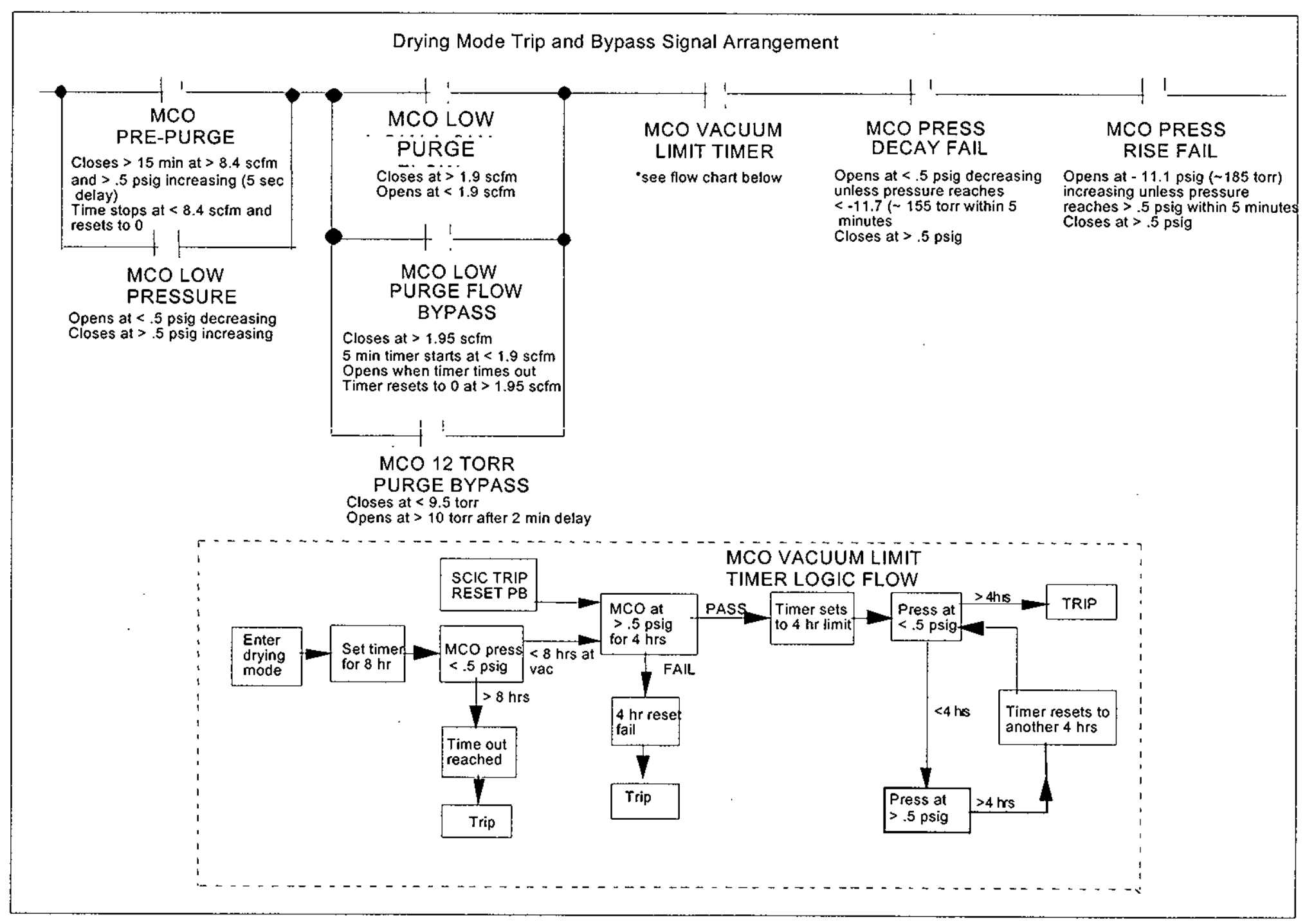


Figure 2-2. SCIC PLC Trip Logic-Detail

SCIC PLC TRIP LOGIC

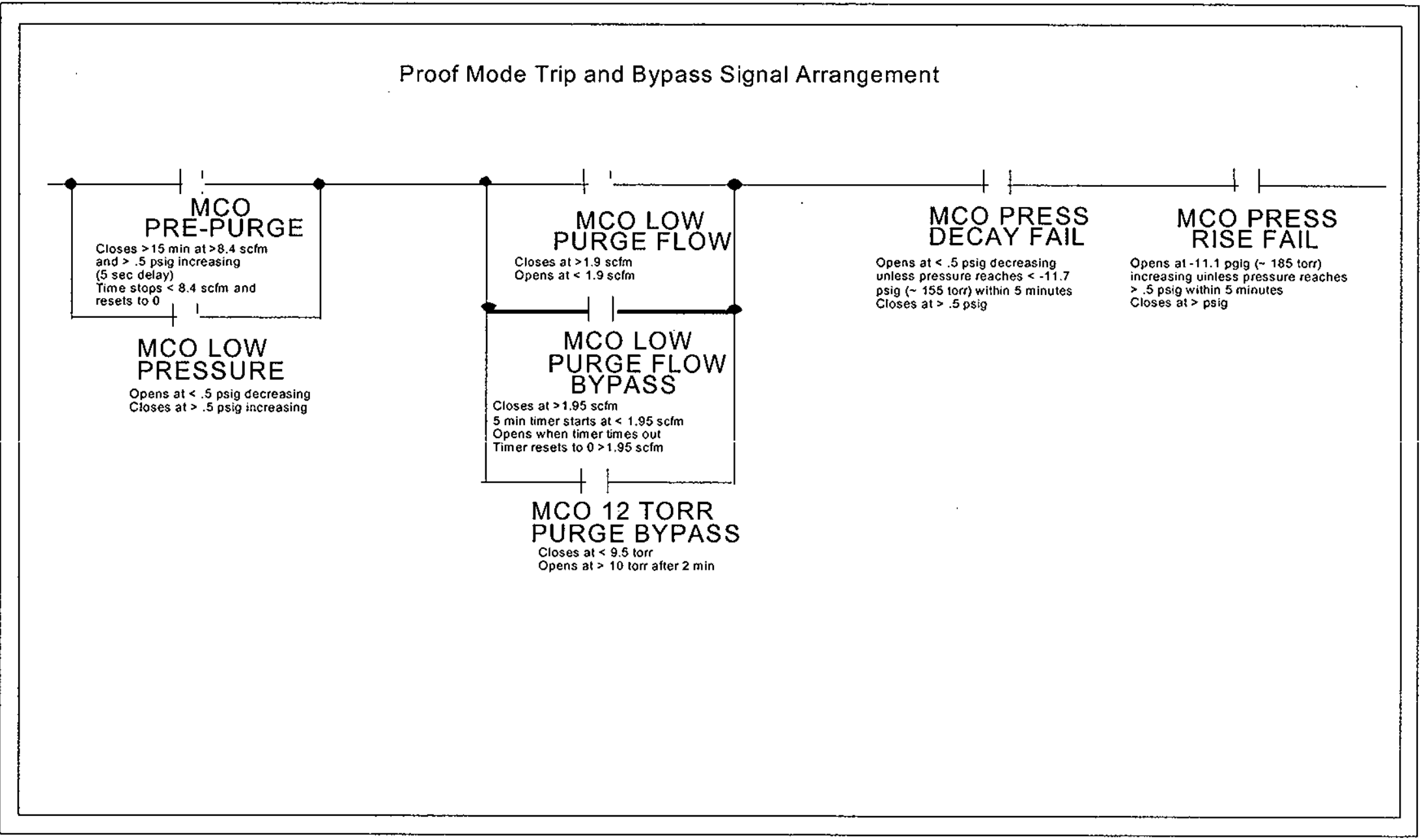




\subsection{REQUIREMENTS AND BASES}

\subsection{General Requirements}

The SCIC system operational and functional requirements are summarized below. Each listing is followed by the basis for the requirement(s) and a synopsis of how the system meets the requirement(s).

\subsubsection{Process Functional Requirements}

\subsubsection{Design Requirements}

1. Requirement: SCIC is generally a standby safety system that has only one process operation - to blowdown any potential water that collected in the SCHe lines after the $\mathrm{PWC}$ rinse is completed. The remainder of the system requirements are to trip if process conditions exceed safety limits.

Basis: This system is required to support the safety functions identified in the Final Safety Analysis Report (FSAR) report (HNF-3553, Annex B, Rev. 0). The SCIC receives signals from the process and facility and responds to off-normal conditions to preclude safety events and defense in depth events. The blowdown function removes any potential water in the long dip tube SCHe entry lines.

How the system meets the requirements: Trip functions are built into the two panels in each active bay. There are both hardwired and Programmable Logic Controllers (PLCs) controlled trips. The blowdown of SCHe lines is accomplished by controlling the opening of valve SCHe-GOV-5*12 and SCHe-GOV-5*31 to blowdown the long dip tube side $\mathrm{SCHe}$ lines.

2. Requirement: Prior to $\mathrm{SCIC}$ activation (i.e., $50^{\circ} \mathrm{C}$ settings), inadvertent $\mathrm{MCO}$ bulk water draining shall be precluded. Electrically interlocking the drain line isolation valves is an acceptable method.

Basis: This system is required to support the safety functions identified in the FSAR report (HNF-3553, Annex B, Rev. 0). Bulk water drain prior to entering the correct SCIC mode would not provide the required trip functions and must be precluded.

How the system meets the requirement: The two safety class drain valves are electrically interlocked to preclude their opening prior to being in the drain mode.

3. Requirement: A feature shall be provided to prevent undetected water addition to the MCO that would invalidate the free water proof condition and creating unacceptable conditions for $\mathrm{MCO}$ storage at the CSB. 
Basis: This system is required to support the safety functions identified in the FSAR report (HNF-3553, Annex B, Rev. 0). The most direct path for water addition into the $\mathrm{MCO}$ is the DI line used during the rinse mode. In addition, under off-normal conditions the PWC drain line could let water back into the MCO. Finally, on the line to the vacuum pump there are two potential sources of water, the condenser and the vacuum pump cooling. There is no postulated method to get undetected water from these two source but as a conservative measure this source is also considered.

How the system meets the requirement: The SCIC interlocks the three sets of MCO isolation valves that have the possibility of adding water. These include the DI supply, the PWC line and the VPS line. In the 7 Pressure Test mode, all six valves are deenergized (closed) and can not be operated by the normal control system. This final mode position at the completion of drying assures no undetected water was added.

\subsubsection{Safety Requirements}

\subsection{Safety Analysis Report Safety Functional Requirements}

The SCIC systems are designed to be redundant and fail-safe. The SCIC systems identified are tied to key process parameter sensors, which when taken as a whole, provide comprehensive and complete detection and response to the upset conditions identified in the accident analyses in Chapter B3.0. The systems also are designed such that internal system failures actuate the safety SSCs to which they are interlocked. This automatic actuation upon failure ensures that loss of monitoring of a key parameter does not degrade the safety function of the SCIC system. The functional requirements needed for the SCIC system to perform its safety functions are as follows:

1. Requirement: Operations and Mode Selection - To be operational before the VPS connectors are attached to the MCO ports and then placed in the proper mode as each process step is performed.

Basis: HNF-3553, Annex B, Section B4.3.1.3 and B4.3.1.4.

How the system meets the requirement: Limiting conditions for operation require that the SCIC system be operational before the process port connections are made to the $\mathrm{MCO}$. The mode selector switch enables or disables the interlocks, provides selected mode status to the PLCs for enabling or disabling the protection logic, passes all mode position status to the non-safety MCS for process operations, and operates selected SCHe valves to purge the $\mathrm{SCHe}$ piping. Table $4-3$ summarizes which trips and interlocks are active during the different mode switch positions.

2. Requirement: Monitoring and Logic - Monitor the input signals from the VPS pressure-transmitters and general-service helium safety-class flow meters, and perform logic and timing functions necessary to ensure that hydrogen and/or oxygen is not accumulating in the MCO. One of the following automatic control strategies shall be employed to prevent hydrogen explosion once bulk MCO water removal is initiated. 
Failure to meet one of these requirements shall initiate an isolation of the process systems from the $\mathrm{MCO}$ and an SCHe purge.

1) The MCO shall be maintained above atmospheric pressure to prevent air ingress (prevents explosion).

2) The MCO hydrogen (from fuel reactions) and oxygen content (via air in-leakage) shall be controlled to below the lower flammability limit.

If logic or timing function parameters indicate conditions wherein hydrogen and/or oxygen could be accumulating beyond acceptable limits, the SCIC system must be capable of automatically initiating an ISO \& PURGE trip. This action will bring the MCO to slightly above atmospheric pressure, prevent the ingress of air, and provide the MCO internal heat transfer medium (helium) for enhanced heat transfer to the TW (annulus) system.

Basis: This system is required to support the safety functions identified in the FSAR report (HNF-3553, Annex B, Rev. 0, Section B4.3.1.3 and B4.3.1.4). MCO pressure and helium flow are monitored to maintain a positive pressure (preclude air ingress) or to maintain the required flow of inert gas (helium) to keep hydrogen levels low. Failure to meet these requirements results in a ISO \& PURGE which will limit the oxygen ingress and purge any oxygen and hydrogen in the $\mathrm{MCO}$.

How the system meets the requirement: For condition 1 above, MCO safety-class pressure monitoring is provided. The pressure sensors are located inside the MCO safety-class isolation valves, and have a detection capability sufficient to detect a drop in pressure and respond to prevent flammable conditions in the MCO. For condition 2. While the MCO oxygen concentration is normally controlled well below flammable conditions consistent with NFPA 69 requirement, this alone does not guarantee that air cannot enter the MCO in the abnormal event of an air ingress event. Therefore, before intentionally entering vacuum mode, the $\mathrm{SCIC}$ requires a continuous purge. The purge needs to be completed to ensure hydrogen concentrations are below the flammability limit. Failure to perform the required purge initiates an ISO \& PURGE. During receipt and prior to bulk MCO water drain, the thermal runaway accident is not possible because the fuel is covered with water. An internal hydrogen explosion will have no onsite or offsite consequence above the guidelines because no particulate is available for release. Each of the PLC trips that are active in the various mode switch positions are discussed in more detail in the following subsections.

To ensure safe conditions during the SCIC DRYING and PROOF modes, the MCO low pressure purge trip remains active and additional PLC trips are activated as discussed below.

- MCO Low Pressure - After draining, when the SCIC system is in the DRAIN and PURGE/FLUSH modes, an MCO low pressure purge trip is active and actuates the ISO \& PURGE if the general-service helium purge pressure falls below the parameter limit of $0.24 \mathrm{lb} / \mathrm{in}^{2}$ gauge $\left(0.5 \mathrm{lb} / \mathrm{in}^{2}\right.$ gauge setpoint $)$. 
Engineering calculations that support the $0.24 \mathrm{lb} / \mathrm{in}^{2}$ gauge parameter limit are listed in SNF-4451, Cold Vacuum Drying Setpoint Determination. This action ensures that air ingress into the $\mathrm{MCO}$ is limited in the event of a line break. These modes require a positive pressure in the $\mathrm{MCO}$ at all times.

- $\quad$ MCO Pre-purge - The MCO pre-purge trip will detect a low purge flow rate or inadequate time of purge prior to pulling a vacuum in the MCO. The MCO low pressure trip is active and the $\mathrm{MCO}$ pre-purge bypasses this trip only if the MCO has been pre-purged with helium at a flow rate of $>8.0$ standard $\mathrm{ft}^{3} / \mathrm{min}$ for $\geq$ 15 minutes. This trip ensures that the gas in the $\mathrm{MCO}$ is below the lower flammability limit for hydrogen prior to going to vacuum, which could introduce oxygen if an undetected air leak is present. Throughout the DRYING and PROOF modes, the MCO is cycled between pressure and vacuum, which requires hydrogen to be maintained at low concentrations when entering vacuum. This requirement is accomplished with the MCO pre-purge, as indicated above. Under normal conditions there should be no time when vacuum is entered with high levels of hydrogen in the MCO. This trip is conservative to account for offnormal conditions (isolated $\mathrm{MCO}$ allowing $\mathrm{H} 2$ buildup) without the proper recovery actions being taken.

- $\quad$ MCO Low Purge Flow, MCO Low Purge Flow Bypass, and MCO 12-torr Purge Bypass - The MCO low purge flow trip monitors the general-service helium supply flow and will activate the ISO \& PURGE trip if the general-service flow is below the parameter limit of 1.5 standard $\mathrm{ft}^{3} / \mathrm{min}$ when above 12 torr and after a 5 -minute delay. This trip is active in the DRYING and PROOF modes. The 1.5 standard $\mathrm{ft}^{3} / \mathrm{min}$ flow rate ensures hydrogen concentrations less than $4 \%$ so that flammable conditions would be precluded, if an air ingress event were to occur which added oxygen.

The lowest vacuum level that can be reached with helium purge active is approximately 50 to 70 torr. The MCO low purge flow bypass allows for a 5 -minute period with no helium flow, which is a process requirement so that a 1.2 torr vacuum can be reached. At a vacuum of 12 torr, the hydrogen concentration is below the amount capable of supporting combustion and no helium purge is required. Helium flow is stopped, which allows the vacuum pump to bring the MCO pressure below the 12-torr parameter limit. If a leak occurs when the 5-minute timer is activated, the vacuum pump is still operational, and after 5 minutes an ISO \& PURGE will be activated. The MCO 12-torr purge bypass trip logic is based on the vacuum reaching $<12$ torr safety parameter for 10 seconds and staying $<12$ torr thereafter. On return above 12 torr, there is a 2-minute delay to allow the MCO low purge to reset as flow is reestablished.

MCO Pressure Decay Fail - During the transition from pressure operation to vacuum, the MCO pressure decay fail trip is activated to ensure no line breaks which would allow continuous air cycling and to detect a degraded vacuum pump, both of which could allow fuel heating beyond limits. This trip also provides a method of detecting a line break in the general helium line downsteam of the 
flowmeters. This line break would invalidate the safety class indication from the general service flowmeters. The $\mathrm{MCO}$ must reach the safety parameter limit of $-11.4 \mathrm{lb} / \mathrm{in}^{2}$ gauge from the parameter limit of $0.24 \mathrm{lb} / \mathrm{in}^{2}$ gauge within 5 minutes from entering vacuum.

- MCO Pressure Rise Fail - Similar to the MCO pressure rise decay trip, the MCO pressure must exceed the parameter limit of $0.24 \mathrm{lb} / \mathrm{in}^{2}$ gauge from a starting point parameter limit of $-10.8 \mathrm{lb} / \mathrm{in}^{2}$ gauge in 5 minutes or an ISO \& PURGE activation will occur. This again ensures no line break has occurred but has no detection method for vacuum pump performance as it did for pressure decay. Calculations that support the use of 5 minutes for the timing period are listed in SNF-4301, Gas Composition Transients in the Cold Vacuum Drying Facility.

- $\quad$ MCO Vacuum Limit Timer (8- or 4-Hour) - A vacuum limit timer trip will limit the time the MCO is under vacuum, defined as being less than $0 \mathrm{lb} / \mathrm{in}^{2}$ gauge parameter limit. This control shall be electronic and not administrative. This requirement assures internal MCO temperatures stay within limits by limiting time under vacuum, which has a reduced thermal conductivity. The 4 hour at pressure will equalize the internal MCO temperatures. Calculations supporting the 8-4-4 cycle requirements are provided in SNF-4301. Thermal heat-up calculations allow for eight hours during the first cycle under vacuum. Since the four-hour cooldown does not return the fuel to the starting temperature, four hours under vacuum is the maximum time allowed for all subsequent cycles. The SCIC $8 / 4 / 4$ timer monitors the time under vacuum to limit heat-up of the fuel as conduction from the fuel to the MCO is reduced. A limit of 8 hours for the initial vacuum cycle and 4 hours for subsequent cycles is provided. The MCO must be returned to pressure for 4 hours between vacuum cycles. Note, a one minute allowance is provided for going under vacuum without instituting the requirement for a 4-hour atmospheric pressure temperature normalization to prevent a false requirement for a 4-hour cooldown should an unexpected short-term pressure fluctuation occur. Exceeding the 8-4-4 cycle requirements will initiate an MCO ISO \& PURGE. This trip is active during 5 Drying mode only. Note that in the 6 PROOF mode, there is insufficient water to support a thermal runaway accident.

- $\quad$ MCO High Pressure - An MCO high pressure trip is active in 2 HEATUP, 3 DRAIN, 4 PURGE/FLUSH, 5 DRYNG, and 6 PROOF modes to preclude challenging the $30 \mathrm{lb} / \mathrm{in}^{2}$ gauge rupture disk because of an improper isolation of the $\mathrm{MCO}$ without a normal or SCHe vent path being available. This trip provides protection against MCO overpressurization and provides defense-in-depth against the thermal runaway reaction accident. An MCO ISO \& PURGE will be activated by the SCIC system if pressure in the MCO exceeds $11.5 \mathrm{lb} / \mathrm{in}^{2}$ gauge (protects the parameter limit of $<25 \mathrm{lb} / \mathrm{in}^{2}$ gauge shown in Table 4-2 and is based on limit of instrumentation). The instrument upper range is $+12 \mathrm{lb} / \mathrm{in}^{2}$ gauge. This trip is not active in 7 Pressure Test mode as there is insufficient water to overpressure the MCO due to improper isolation. 
3. Requirement: Annulus Low Water Level Alarm - Monitor the TW (annulus) system annulus water low level switch and provide an alarm to the operators if the level falls below the lower limit. Water shall be maintained in the MCO cask annulus above the level of the highest fuel or scrap basket under all DBA conditions A safety-class alarm to the CVDF control room shall be initiated if water level goes below the highest fuel or scrap basket for non-seismic events.

Basis: HNF-3553, Annex B, Section B4.3.1.3 and B4.3.1.4. The SCIC receives signals from the annulus water level low level switch to alert the operator of a low level. An alarm provides the operator time to respond to a loss of annulus water, which could result in a thermal runaway without corrective action. Water in the annulus provides the cooling medium to the bay to maintain MCO fuel temperatures within limits.

How the system meets the requirement: The TW (annulus) system low level switch provides protection from a thermal runaway reaction by alerting the control room operators to situations where the annulus water level is. A safety-class alarm to the CVDF control room is initiated if water level goes below the highest fuel or scrap basket for non-seismic events. This control room alarm produces an audible and visual alarm which must be acknowledged by the operator to silence the alarm.

4. Requirement: Tempered Water High Temperature Trip - Monitor the TW (annulus) system annulus inlet water temperature switch and de-energize electrical power to the TW (annulus) system heater and pump, if the temperature is above the setpoint limit. Heat input to the MCO from the TW heater shall be limited. A safety-class temperature control scheme shall be employed to monitor and prevent temperature inputs to the $\mathrm{MCO}$ from exceeding either the lower or upper temperature setpoint. The lower temperature setpoint range shall be between $10^{\circ} \mathrm{C}$ and $25^{\circ} \mathrm{C}\left(50^{\circ} \mathrm{F}\right.$ and $\left.77^{\circ} \mathrm{F}\right)$ and the upper shall be between $45^{\circ} \mathrm{C}$ and $50^{\circ} \mathrm{C}\left(113^{\circ} \mathrm{F}\right.$ and $\left.122^{\circ} \mathrm{F}\right)$. A means to prevent heat from reaching the $\mathrm{MCO}$ (i.e., heater shutoff or stopping flow) shall be initiated if the temperature setpoint is exceeded. Any actuation shall require a manually operated "reset."

Basis: This system is required to support the safety functions identified in the FSAR report (HNF-3553, Annex B, Rev. 0, Section B4.3.1.3 and B4.3.1.4). The temperature limit is based on the limits used for the thermal calculation for the thermal runaway accident. The SCIC precludes excessive heat into the MCO to protect the assumptions of the thermal calculated, which used $50 \mathrm{deg}$. $C$ as the upper water temperature value.

How the system meets the requirement: A safety-class high temperature trip will deenergize the TW heater. The TW high temperature switch trip provides protection from a thermal runaway reaction by limiting the heat from the TW (annulus) system. This is done by tripping the TW heater if the TW exceeds the $50 \mathrm{C}$ parameter limit. The TW recirculation pump is also de-energized but is not credited in the safety basis. Any actuation requires a manually operated "reset." This system is mode independent and is active throughout the $\mathrm{MCO}$ processes. 
5. Requirement: Process Upset Conditions - Automatically initiate an ISO \& PURGE trip under process upset conditions, including loss of power.

Basis: HNF-3553, Annex B, Section B4.3.1.3 and B4.3.1.4. The SCIC was designed to be failed safe and require no "qualified or IE" power to perform it's safety function. A loss of electrical power must initiate a ISO \& PURGE to be fail safe. Seismic events could affect the operation of the non-qualified portions of the process systems. The seismic trip assures these portions are isolated from the safety class side. In addition, a number of instruments that feed the SCIC are not seismically qualified, the function of these items is meet with the seismic trip of the ISO \& PURGE and TW heater and pump shutdown.

How the system meets the requirement: Both loss of electrical power and a seismic event are common mode failures that must be precluded from affecting the safety function of the SCIC. To meet this requirement, the design of the SCIC system ensures activation of an MCO ISO \& PURGE and trip of the TW heater under process upset conditions. Included in this protection are loss of electrical power and a seismic event that activate the relays for MCO ISO \& PURGE and shutdown of the TW (annulus) system heater and pump.

6. Requirement: Control Room Alarms - Provide safety-class alarms for BAY ISO \& PURGE, ANNULUS LOW LEVEL, and the defense-in-depth PWC LOW FLOW alarm to the CVDF control room.

Basis: HNF-3553, Annex B, Section B4.3.1.3 and B4.3.1.4. These alarms require immediate operator action and the two alarms have safety class functions. To assure that there is no loss of SCHe under non-seismic conditions and to initiate operator response for high bay temperature, the ISO \& PURGE alarm is provided. The Annulus low level alarm protects the annulus water level and requires operator action. The PWC alarms provide defense in depth to aid in maintaining low hydrogen/oxygen concentrations in the PWC receiving tanks.

How the system meets the requirement: The SCIC system contains safety-class redundant annunciators that provide alarms for BAY ISO \& PURGE, ANNULUS LOW LEVEL, and PWC LOW FLOW. Activation of the alarms alerts the operator that immediate corrective action is required. Although included on the safety-class annunciator, the PWC LOW FLOW alarm is not required to meet a safety class function.

7. Requirement: Seismic Safe Shutdown -- Seismic recorders shall be used to detect, record, and trip on a seismic event exceeding a level in excess of normal Uniform Building Code (UBC) values, which guarantees no damage to non-seismic components and structures (suggest a setting of $0.05 \mathrm{~g}$, triaxial). This seismic trip shall be safety class with self-contained battery backup power to operate during and after an earthquake for a minimum of 30 minutes. The SCIC must be capable of receiving signals from the 
seismic recorder and trip component and, upon ground motion acceleration above the setpoint, automatically activating MCO ISO \& PURGE. In addition, the SCIC will provide shutdown of power to the TW (annulus) system heater..

Basis: This system is required to support the safety functions identified in the FSAR report (HNF-3553, Annex B, Rev. 0, Section B4.3.1.3 and B4.3.1.4). The SCIC system includes seismic monitoring functions to 1 . Protect the safety function during or after an earthquake and 2. Preclude the need for extensive qualification on some instruments and piping. By tripping on a seismic event and isolating the non-qualified piping, the piping and instrument function do not have to seismically qualified. For example, the TW heater must be shutdown to account for the effects on the TW high temperature switches that are responsible for the high temperature trip. These devices are not seismically qualified and therefore can not be relied upon to function under earthquake conditions. The ISO \& PURGE trip is similar as it accounts for various process signals that are also not seismically qualified. Note that the Safety Equipment List shows seismic qualified required but this is for "boundary only". Boundary only assures no leakage not circuit function after a seismic event.

How the system meets the requirement: The seismic trip is designed to detect a seismic event, isolate the $\mathrm{MCO}$, and actuate the $\mathrm{SCHe}$ system. In addition, a seismic event will shut off power to the TW (annulus) system heater. Two methods are used to preclude fault trips by the seismic monitoring equipment. First, the three sensors (each are triaxial) are located in three different process bays $(2,3$, and 4$)$, which precludes vibrations in one bay from tripping all three sensors. Second, each auctioneering logic circuit requires two of the three sensors to be in alarm to initiate a trip of each train. The seismic shutdown system is designed to performance category 3 criteria.

The accident analysis identified that a DBE could damage safety-class systems or components. Some components may not be operable after a seismic event to meet their safety function. To eliminate the need for seismic qualification, the seismic trip will perform the safety function (i.e., trip the MCO ISO \& PURGE and de-energize the TW heater).

8. Requirement: High Bay Temperature - Monitor the process bay temperature. Initiate $\mathrm{SCIC}$ trip, isolate the $\mathrm{MCO}$, and purge via the SCHe system if the bay air temperature exceeds the setpoint.

Basis: HNF-3553, Annex B, Section B4.3.1.3 and B4.3.1.4. The high bay temperature trip and subsequent ISO \& PURGE alarm in the control room provide assurance that the calibration limits of the vacuum gauges (PT $1 * 08$ and $1 * 10$ ) have not been exceeded, 105 ${ }^{\circ} \mathrm{F}$. In addition, the actuation of the alarm on the $\mathrm{SC}$ Annunciator will alert operations of high bay temperature which could exceed the environmental temperature limit of $115^{\circ} \mathrm{F}$. Exceeding the $105^{\circ} \mathrm{F}$ limit could affect accuracy of the vacuum pressure measurement which would affect the SCIC safety function. Exceeding the $115^{\circ} \mathrm{F}$ environmental limit would invalidate assumptions used in the thermal models. 
How the system meets the requirement: High bay temperature sensor activation occurs when the mode selector switch is moved to the HEATUP position and continues throughout the remainder of the process. The process bay temperature monitoring system is designed to trip the SCIC system relay and activate an ISO \& PURGE, if the bay temperature exceeds $105 \mathrm{~F}$. Design analysis identified the possibility that elevated temperatures in the process bay could result in instrumentation and control inaccuracy and malfunctions that could affect the function of safety-class systems. Thus, the MCO is placed into a safe configuration if temperatures exceed the $105 \mathrm{~F}$ parameter limit.

Operator action is required upon receiving an ISO \& PURGE alarm. This would include verifying bay temperatures are within limits.

9. Requirement: Nonqualified Signal Protection - Provide protection from any nonsafety operational controls (e.g., coming from the monitoring and control system [MCS]) that could affect or degrade the safety-class operation of the SCIC system.

Basis: HNF-3553, Annex B, Section B4.3.1.3 and B4.3.1.4. To assure isolation from the affects of a non-safety system to the SCIC electrical separation is required.

How the system meets the requirement: The SCIC system provides non-safety-class signals to the facility MCS for normal control, indication, and alarms. The signals from the SCIC system include all analog signals (flow and pressure), SCIC internal logic status, and trip and alarm contact status. All signals from the SCIC system are electrically isolated from any nonsafety system, including the MCS. Buffering is provided for these analog signals and relay separation is provided for other discrete signals, including the seismic monitoring system. Communications is also buffered to provide trip information from the SCIC programmable logic controllers (PLC) and the seismic sensors.

10. Requirement: Sensor Error - Account for sensor error in trip setpoints so that operations are within specifications, process function monitoring does not lead to unsafe conditions, and safe shutdown is accomplished as anticipated.

Basis: HNF-3553, Annex B, Section B4.3.1.3 and B4.3.1.4. This assures that the trip will occur prior to exceeding the parameter limit by accounting for instrument errors.

How the system meets the requirement: Analysis has been performed for all sensor loops associated with functional operation of the SCIC system trip setpoints to allow for instrument error (see SNF-3091). Trip setpoints shown in Table 4-2 ensure critical parameters will not be exceeded for all functional requirements. For all analog signals coming from pressure and flow, an average of the signal is performed to remove instrument spikes that may occur.

11. Requirement: Testing Functions - Capable of providing periodic testing of the SCIC system functional operations. 
Basis: HNF-3553, Annex B, Section B. B4.3.1.3 and B4.3.1.4. Calibration and testing is required to assure the safety function is functioning properly. Provisions are provided to accomplish these tasks.

How the system meets the requirement: The local operating panels in each process bay provide test switches to perform operational tests on the following SCIC functions: TW (annulus) system high temperature trip, bay high temperature trip, and TW (annulus) low-level alarm. A key switch on the panel enables the test. Once enabled, pressing the appropriate test button can simulate a trip. The bay high temperature test will initiate a ISO \& PURGE; the TW high temperature trip test will de-energize the TW heater and pump; and the TW (annulus) low-level alarm will active the safety-class annunciation in the control room. Test features are also provided on the seismic auctioneering panel (CP 120 and CP 121) for the three seismic sensors.

Other functional tests or calibrations require the use of a SCIC calibration and test computer unit that tests logic functions and allows for detailed calibration functions. The calibration and test computer is part of the SCIC system but is not normally connected to the SCIC PLC.

12. Requirement: Single-Failure Evaluation - To be single-failure proof in accordance with IEEE 603-1991, and IEEE 379-1994, Application of the Single-Failure Criterion to Nuclear Power Generating Station Safety Systems.

Basis: HNF-3553, Annex B, Section B4.3.1.3 and B4.3.1.4. To assure that common mode failures will not jeopardize the safety function of the SCIC, an analysis is required to review potential off-normal conditions.

How the system meets the requirement: The SCIC system has been designed to be single-failure proof and provides redundancy for all sensors and control modules. Singlefailure analysis for the SCIC system logic controller was performed as a procurement requirement by the vendor. Single-failure analysis of the SCIC system has been performed and is documented in SNF-4290. Responses to an event are unchanged by failure of any one component due to the independent action of the second SCIC system instrumentation.

13. Requirement: Seismic Qualification - Meet performance category 3 seismic requirements for all process bay SCIC equipment.

Basis: HNF-3553, Annex B, Section B4.3.1.3 and B4.3.1.4. The SCIC continues to provide the required safety function after an earthquake of $0.26 \mathrm{~g}$ or less. To maintain this function, the SCIC portions responsible are seismically qualified. This includes the final relay logic, seismic monitoring equipment, TW heater starters. Other components are not included as their function is no longer required, such as the flow and pressure transmitters.

How the system meets the requirement: The whole of the SCIC systemis seismically qualified, with the exception of the SCIC Annunciator. These two panels are not required 
to be seismically qualified the SCIC will automatically perform all needed safety functions without operator action. In addition, the loss of the annunciator after a seismic event strong enough to fail items in the control room will be obvious to the operator or to the site response team.

Process sensors (pressure and flow) are not seismically qualified for operability (only pressure boundary as required) because the seismic monitoring trip will satisfy the safety function after a seismic event. Seismically qualified local indication is provided for accident recovery monitoring. These components are not part of the SCIC system.

Engineering calculations demonstrating the adequacy of the performance category 3 SCIC system are listed in SNF-3001. In addition, the seismic trip portion of the SCIC system will place the $\mathrm{MCO}$ process system in a safe-shutdown mode if a major seismic event occurs. All active SCIC equipment that is required to maintain functional operability during and after a seismic event has been seismically qualified by shake-table testing. The safety-class cabinets are bolted to the process bay floor to meet performance category 3 seismic requirements.

3.1.1.2.3 Safety Significant Requirements. There are no safety significant requirements for this system.

3.1.1.2.4 Other Safety Requirements. There are no other safety significant requirements for this system.

3.1.1.3 Environmental Requirements. There are no environmental requirements for this system.

3.1.1.4 Mission-Critical Requirements. There are no mission-critical requirements for this system.

3.1.1.5 General Requirements. There are no unique general requirements for this system not previously addressed.

\subsubsection{Subsystem and Major Components}

3.1.2.1 Multi-Canister Overpack Isolation and Purge (MCO ISO \& PURGE). An MCO ISO\&PURGE trip places the effected bay into the following conditions: VPS, generalservice helium, $\mathrm{PWC}$ isolation valves closed (MCO is isolated) and $\mathrm{SCHe}$ valves open ( $\mathrm{MCO}$ is purged). The eight $\mathrm{MCO}$ isolation valves and four $\mathrm{SCHe}$ isolation valves are controlled by the SCIC system through relay output contacts. The following parameters can cause an MCO ISO\&PURGE trip:

- $\quad \mathrm{MCO}$ pressure (both positive pressure and vacuum)

- Helium flow rate

- $\quad$ Process bay high temperature switches

- Seismic trips

- Timer and vacuum trips. 
The MCO pressure and helium purge rates are used to prevent explosive accumulations of hydrogen and oxygen. MCO high pressure specifically provides for a safety-class vent path from the MCO. MCO pressure is also used for the 8-4-4 vacuum limit timer. The process bay high temperature is used to protect against the effects of high bay temperature on the accuracies of the safety-class instrumentation. Separate temperature switches are provided that, if exceeded, will initiate an MCO ISO\&PURGE.

A vacuum limit timer monitors the time under vacuum to limit heatup of the fuel. This vacuum condition reduces thermal conduction from the $\mathrm{MCO}$. After the vacuum cycle, a minimum time above atmospheric pressure is required to cool down the fuel. The SCIC system ensures that exceeding the time under vacuum, or returning to vacuum without first meeting the minimum time above atmospheric pressure, will result in an $\mathrm{MCO}$ ISO\&PURGE.

- Tempered Water. The TW safety class portion of the overall SCIC system consists of the TW high-temperature trip and the TW low-level annunciation. Other specified nonsafety-class functions are provided through interfaces with non-safety systems. The TW high-temperature protection portion of the SCIC equipment is fully automatic and functional at all times except for periods of maintenance or testing.

- Seismic Monitoring. Seismic recorders are used to detect, record, and trip during a seismic event exceeding $0.05 \mathrm{~g}$, triaxial, any direction. Logic is used to preclude fault trips by locating each of three sensors in process bays 2,3 , and 4 and by using two out of three (2/3) logic to initiate a TW trip and an MCO ISO \& PURGE trip.

3.1.2.2 Control Room Safety Class Annunciator. This portion of the SCIC system contains two redundant annunciators that provide safety-class (SC) and Defense-In-Depth alarms. BAY PURGE, ANNULUS LOW LEVEL and PWC LOW FLOW make up the alarms provided to the control room operator. The BAY PURGE alarm notifies the operator when an ISO \& PURGE trip has occurred. The ANNULUS LOW LEVEL alarm is generated from relay logic directly from the low-level switches on the TW water piping connections. The PWC LOW FLOW is an indication of a low purge flow or a purge that was interrupted during either PWC Pre-Purge or Post-Purge. An audible horn and blinking lights indicate the receipt of any of the 12 alarms (four bays, three types of alarms for each bay). NOTE: The SCIC is designed, built, and tested as safety-class although certain functions are safety-significant or Defense-In-Depth. This was done to minimize impacts to the design and construction as further analysis was being performed that could affect its safety classification and to simplify the design to meet separation requirements. The PWC purge failure alarms are classified as Defense-In-Depth.

\subsubsection{Boundaries and Interfaces}

The SCIC system is powered from the facility non-safety power. Isolation between the nonsafety power and the internal power used by the SCIC is provided, fused in all cases, except the safety-class annunciator, which has an uninterruptible power supply (UPS); and the seiosmic monito, which has power supplies and battery backup. No class $1 E$ power is supplied or required by the SCIC system as failure of power results in the safety-class protective function actuation, 
fail-safe criteria. The safety-class annunciator's UPS provides 30 minutes of continuous operation to provide information after a loss of site power. This feature is not required for safety, but is a conduct of operations enhancement. Failure of the annunciator after a loss of power will not result in an accident nor degrade the safety function of the SCIC system.

The SCIC and SCHe systems are automatic systems that operate independently of the operator once they are activated. The systems initiate and maintain the MCO in a fail-safe shutdown mode until the operator has completed the recovery procedure. Manual interaction (reset) is required by an operator to take the system out of the fail-safe shutdown mode to restore the system to normal operation.

NOTE: In the following descriptions, an asterisk $(*)$ will appear in the second digit of a component or instrument tag number. The asterisk denotes the CVDF bay number in which the component or instrument resides (e.g., VPS-GOV- $1 * 05$ represents valves VPS-GOV-1205, VPSGOV-1305, VPS-GOV-1405, and VPS-GOV-1505 in bays 2 through 5, respectively).

The SCIC system interfaces with the following safety-class MCO isolation valves as shown on Figure 3-1.

- $\quad$ MCO drain: PWC-GOV-1*03 (A) and PWC-GOV-1*30 (B)

- Vacuum system to pump: VPS-GOV-1*05 (A) and VPS-GOV-1*09 (B)

- Vacuum de-ionized/helium (DI/He) line: VPS-GOV-1*11 (A) and VPS-GOV-1*17 (B)

- $\quad$ Process helium: He-GOV-1*06 (A) and He-GOV-1*02 (B)

- $\quad \mathrm{SCHe}$ system purge long dip tube side: SCH3-GOV-5*12 (A) and

- $\quad \mathrm{SCHe-GOV-5*31(B)}$

- $\quad \mathrm{SCHe}$ system purge short dip tube side: SCHe-GOV-5*51 (A) and SCHe-GOV-5*71 (B) 
Figure 3-1. Cold Vacuum Drying Process Connections and Instrument Basics

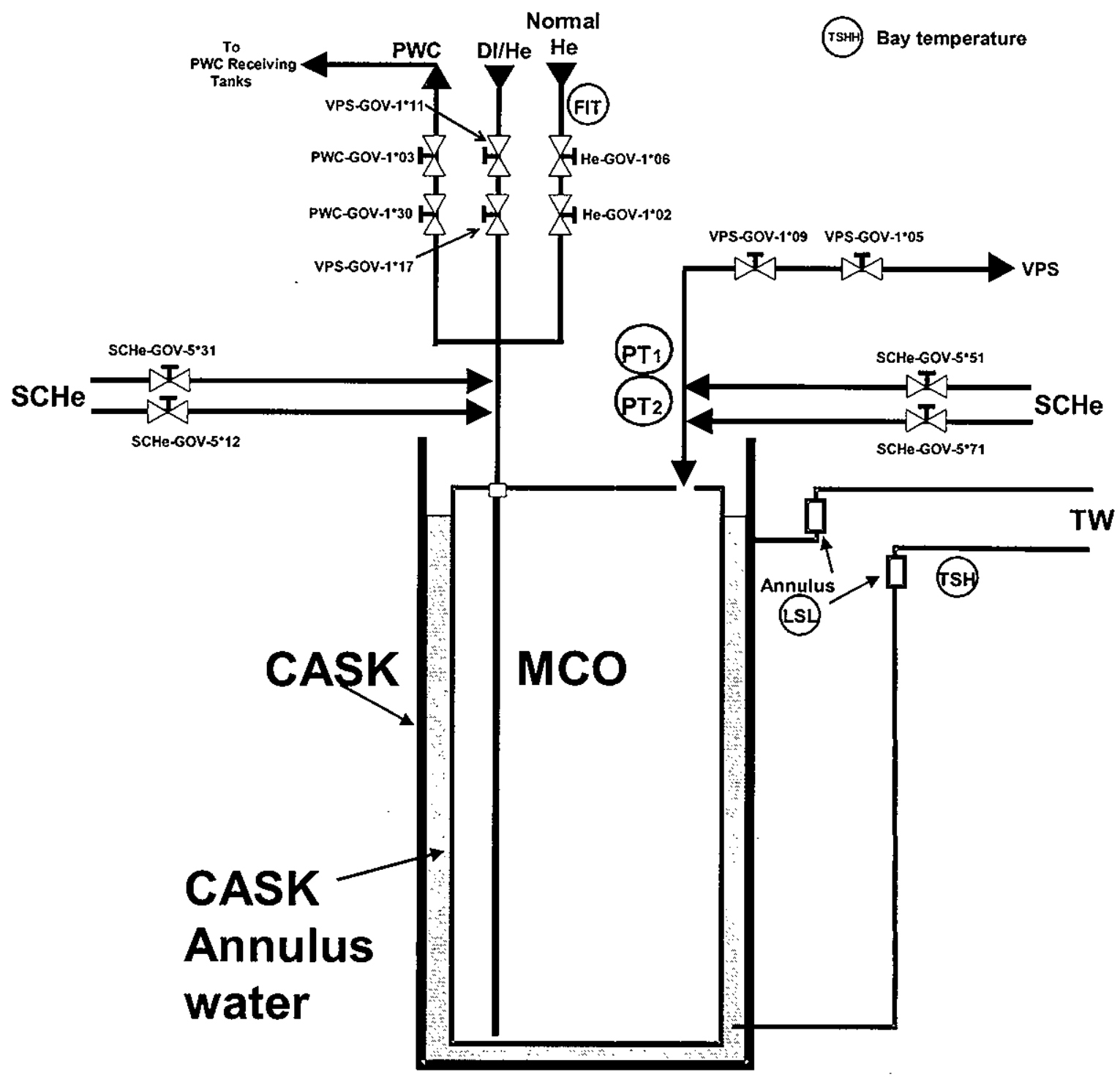

Note: All instruments, PT, FIT, TSH and LSL have two components per bay.

PT1: Pressure Transmitter (PT 1*36, 1*37)

PT2: Pressure Transmitter (Vacuum) (PT 1*08, 1*10)

FIT: Flow Indicating Transmitter (FIT 1*20,1*21)

TSH: Temperature Switch High (TSH 1*28, 1*29)

LSL: Level Switch Low (LSL $1 * 24,1 * 25$ )

TSHH: Bay Temperature Switch High High (TSHH 1*38, 1*39)

Note: The * represents 2 through 5 for bays 2 - 5 


\subsubsection{Codes, Standards, and Regulations}

The SCIC system was designed in strict accordance with the following material and fabrication standards:

- $\quad$ Code of Federal Regulations (CFR)

10 CFR 72 "Licensing Requirements for the Independent Storage of Spent Nuclear Fuel and High-level Radioactive Waste"

- American Society of Mechanical Engineers (ASME)

NQA-1Quality Assurance Requirements for Nuclear Facility Applications

- Institute of Electrical and Electronics Engineers (IEEE)

379 Standard Application of the Single Failure Criterion to Nuclear Power Generating Station Safety Systems

384 Standard Criteria for Independence of Class 1 E Equipment and Circuits

603 Standard Criteria for Safety Systems for Nuclear Power Generating Stations

627 Standard Design Qualifications of Safety System Equipment Used in Nuclear Power Generating Stations

NOTE: The annunciation of the TW (annulus) low-level alarm is safety-class. Although the annunciator does not directly prevent a safety-class event, it supplies information to the operator to initiate corrective actions. Since the U.S. Nuclear Regulatory Commission (NRC) does not classify this type of system as a reactor shutdown system, the requirement of this system is that it must be highly reliable. To prove reliability, the system is designed with redundant channels. In addition, the design meets the above referenced IEEE specification, including single failure criteria and isolation. IEEE-344, Seismic Qualification, is not required.

344 Seismic Qualification of Class 1 E Equipment for Nuclear Power Generating Stations

7-4.3.2 Standard Criteria for Digital Computers in Safety Systems of Nuclear Power Generating Stations

NOTE: IEEE-308 requirement for Class 1E power is not applicable to the SCIC system as all loss-of-power conditions are fail-safe. The requirements of IEEE 323 for qualifying class $1 \mathrm{E}$ for Nuclear Power Generating is not applied since the environmental requirements are "mild" as defined in this document. This is based on the low radiation levels in the CVDF, no steam environment or other 
environmental conditions that would affect aging or performance outside the normal environmental conditions such as temperature and humidity.

- National Fire Protection Association (NFPA)

$70 \quad$ National Electrical Code

- National Electrical Manufacturers Association (NEMA)

ICS 6 Enclosures

- U.S. Nuclear Regulatory Commission

Regulatory Guide 1.152, Criteria for Digital Computers in Safety Systems of Nuclear Power Plants

- Underwriters Laboratories

Electrical Appliance and 1994 Utilization Equipment Directory.

\subsubsection{Operability}

The majority of the SCIC system is required to be operational before the MCO process connections are made. The SCIC system and interfacing systems are considered operable and processing in a given process bay proceeds if the following occur:

- $\quad$ Power is being supplied to the SCIC system from the facility.

- Both train A and train B SCIC system programmable logic controllers (PLCs) are functioning, receiving input, and capable of actuating their isolation and purge valves.

- The control room safety-class annunciators are operating.

- All safety transmitters and process switches for that process bay are functioning (PT$1 * 08 ; \mathrm{PT}-1 * 10 ; \mathrm{PT}-1 * 36 ; \mathrm{PT}-1 * 37$; FIT-1*20; FIT-1*21; TSH/TSHH-1*38;

TSH/TSHH- $* 39$; TSH- $1 * 28$; and TSH-1*29).

- All safety isolation valves and their associated actuators, solenoid valves, and relays are functioning and able to receive signals from the SCIC system (He-GOV-1*02; He-GOV$1 * 06$; PWC-GOV-1*30; PWC-GOV-1*03; VPS-GOV-1*05; VPS-GOV-1*09; VPSGOV-1*17; and VPS-GOV-1*11).

- $\quad$ All SCHe system purge valves and their associated actuators, solenoid valves, and relays for their respective process bay are functioning and able to receive signals from the $\mathrm{SCIC}$ system PLCs (SCHe-GOV-5*12; SCHe-GOV-5*31; SCHe-GOV-5*51; and SCHe-GOV$5 * 71$ ). 
- The SCIC system seismic recorders and trip component are operational.

- The SCIC system process bay temperature monitor is operational in a process bay when an $\mathrm{MCO}$ is being processed in that process bay.

- The PWC seismic pump interlock is operational. NOTE: This feature is Defense-InDepth and is not credited or required by the Safety Analysis Report (SAR).

The following assumptions associated with the SCIC system require TSRs, which are documented in HNF-3673, Technical Safety Requirements, to ensure performance of its safety functions.

- The SCIC system is operational before the MCO process port connections are made.

- The other systems that provide signal input to the SCIC system (i.e., pressure transmitters, flow-indicating transmitters, TW high temperature switches, cask-MCO annulus water low-level switches, process bay temperature switches, and seismic trips) are operational.

- The seismic trip component is operational when an MCO is being processed.

- The process bay temperature monitor in a process bay is operational when an MCO is being processed in that bay.

- Standard calibrations of the SCIC system and functional testing of each SCIC train for ISO \& PURGE trip shall be performed at periodic intervals (see setpoints in Table 4-2).

\subsection{Special Requirements}

\subsubsection{Radiation and Other Hazards}

There is no appreciable radiation field exposure to the equipment of the SCIC; thus, no effect of radiation is considered. (Reference HNF-3229, Rev. 1, DRAFT, dated 1/18/99, paragraph 1.4 .3 Radiation.)

\subsubsection{ALARA}

As Low as Reasonably Achievable (ALARA) features are considered throughout the design of the SCIC system. For example, the mode switches and safety-class annunciator are both located in the control room. It is anticipated that no routine access to the bays is required to operate the SCIC system. All required status indication is being provided to the MCS display in the control room.

\subsubsection{Nuclear Criticality Safety}

This is not applicable to this system. 


\subsubsection{Industrial Hazards}

The SCIC plays a part in the control of hydrogen/oxygen explosions as outlined above. The CVD system with the support of the SCIC system meets the requirements of both the project requirements $(<\mathrm{LFL})$ and the National Fire Protection Agency (NFPA) $(<1 / 4 \mathrm{LFL})$. The SCIC system presents minimum industrial hazards, including electrical.

\subsubsection{Operating Environment and Natural Phenomena}

All SCIC equipment located in the process bays is seismically-qualified to demonstrate operability and anchorage adequacy during a Design Basis Earthquake (DBE) event. Panels or equipment located outside the bays are not seismically-qualified and do not impact the SCIC safety function during or after an earthquake.

All SCIC system components, instrumentation, controls, and support structure are designed for performance category 3, as defined in DOE-STD-1020-94. The SCIC equipment is protected from high winds, tornadoes, floods, lightning, and snow load by the placement and design of the $\mathrm{CVDF}$. The SCIC equipment is located in a mild environment with no significant aging mechanism present. Therefore, qualified life is not required as defined in IEEE-323.

The following represent the normal and accident environmental limits the SCIC may be subject to:

Table 3-1. Operating Environmental Limits

\begin{tabular}{|l|c|c|}
\hline & Temperature $^{\circ} \mathbf{F}$ & Humidity (RH\%) \\
\hline Normal Low & 60 & 40 \\
\hline Normal High & 75 & 25 \\
\hline Accident Low & 40 & 60 \\
\hline Accident High & 115 & 22 \\
\hline
\end{tabular}

The SCIC components are not sensitive to variation in barometric pressure or humidity. Since the CVD process upsets do not produce relatively high pressures or high radiation (as this relates to equipment limitations), neither was considered in the design of the equipment.

All active equipment required to maintain functional operability during and after a seismic event were seismically-qualified by shake table testing. The testing was performed in accordance with the procedures outlined in IEEE-344. The input excitation was based on the U.S. Department of Energy (DOE) requirements (DOE-STD-1020-94) for evaluation by testing. A damping value of 2 percent was utilized. 


\subsubsection{Human Interface Requirements}

During operations, the operator interfaces with the SCIC system through the mode switch panel in the control room and the safety-class annunciator. For the MODE switches, numbers as well as text describing the mode position were added to give two indications of the required switch positions. For example, the operating procedure would direct the operator to select " 4 Drying mode for Bay 2, HS-6707." The annunciator provides industrial standard format for alarm receipt, acknowledgment, and auto reset.

\subsubsection{Specific Commitments}

There are no specific commitments applicable to this system.

\subsection{Engineering Disciplinary Requirements}

\subsubsection{Civil and Structural}

The supports and anchorage for SCIC equipment were designed for seismic loads based on the Design Response Spectra (DRS) for performance category 3 in the 100 and 200 Areas. The DRS has a peak ground acceleration of $0.26 \mathrm{~g}$ and a vertical peak ground acceleration of $0.18 \mathrm{~g}$. Seismic accelerations were applied in the three orthogonal directions to verify the structural adequacy of the supports and anchorage. Structural steel allowable stresses conform to the Steel Construction Manual, Ninth Edition. Load combinations for total seismic demand for anchor bolts utilized the method of finding the square root of the sum of the squares (SRSS).

\subsubsection{Mechanical and Materials}

This is not applicable to this system.

\subsubsection{Chemical and Process}

This is not applicable to this system.

\subsubsection{Electrical Power}

The SCIC system receives single-phase $120 \pm 10$ volts at $60 \pm 1 \mathrm{~Hz}$ power from non-safety site power. Specific requirements for isolation of non-safety to safety are provided in the IEEE-384 requirements. There is no safety requirement to maintain power after a loss of site power. Failsafe conditions are met whenever internal SCIC power or signals are lost. To provide post seismic evaluations, the seismic monitoring equipment has battery backup. To allow for conduct of operations response to a loss of site power, the safety-class annunciators have 30 minutes of UPS. This feature is not required for safe shutdown but enhances the operation after a loss of power. 


\subsubsection{Instrumentation and Control}

The SCIC system is an instrumentation and control system.

1 Requirement: The following functions shall be provided for logic trains $\mathrm{A}$ and $\mathrm{B}$.

- Safety-class, operator-controlled "MODE" switches to disable ("BYPASS" position) and enable (various mode positions) the safety-class logic A and B trains shall be provided in the control room. These switches shall have bay-specific key locks (i.e., one key for both logic trains but different for each bay).

- Shutdown actuation switches shall be provided at the SCIC panel in each bay and in the control room. Either train A or B push button shall initiate the safety-class purge and MCO isolation of that specific train. A method shall be employed to prevent inadvertent actuation and to provide non-safety illuminated status when the purge has been activated by these switches.

- Safety-class logic trip or alarm status indication, with lamp test button, shall be provided. As an example, the following types of signals would be displayed:

$\begin{array}{ll}- & \text { Seismic monitor trip } \\ - & \text { Tempered water HI TEMP trip } \\ - & \text { Low cask water level alarm } \\ -\quad & \text { Bay Hi TEMP trip }\end{array}$

- A safety-class "logic test" key-locked switch shall be provided at each bay to allow for testing. In addition, individual switches for testing each logic train signal shall be provided. The status light shall verify the actuation of the logic signal via this test. Note: Due to the complexities of the logic in the SCIC PLC, a simple test switch can not perform certain tests. This includes the logic for MCO Low Pressure, MCO Low Flow, MCO Pre-Purge, MCO Vacuum Limit Timer, MCO Pressure Rise and Decay Failure and the two PWC Pre and Post Purge Alarms.

- $\quad$ Signals shall be provided from all powered safety-class instruments to the non-safety MCS. This includes safety logic signals, alarms, and timer counters used for SCHe purge initiation. Electrical isolation shall be provided, as required.

- A reset button shall be provided to reset the high heat input (HI TEMP) TW trip. The actual logic shall clear automatically when the condition is below the reset value; however, the trip status shall remain until this reset button is pushed.

- For any timers used an automatic means to reset timer shall be provided.

Basis: These requirements are necessary to fulfill the safety functions of the SCIC System. 
How the system meets the requirement: The design incorporates these requirements as described throughout this document.

\subsubsection{Computer Hardware and Software}

The SCIC contains both computer hardware and software. The majority of software resides in the SCIC PLC in each of the four active bays, 2 thorough 5. In addition, the Calibration and Test Computer has both commercial software (DOS, BIOS, Operating System) as well as specialized software to calibrate and test the SCIC PLC.

The following documents are provided per ASME NQA-1-1994, Subpart 2.7 requirements: Computer Software Requirements Specification (CSRS), computer software design description (CSDD), and computer software user documentation (CSUD) .

NOTE: The Framatome Technology "STAR" PLC hardware and software are specified to meet NRC equivalency for nuclear plant shutdown systems. The STAR PLC was previously accepted by the NRC due to its diverse processing and firmware architecture, and its strong quality assurance (QA) software.

\subsubsection{Fire Protection}

The SCIC panels are not rated or built to withstand fires. Effects from a fire outside the bay are protected against in software and by buffering from the control room to the bay panels. Fire that could affect the bay panels is precluded.

\subsection{Testing And Maintenance Requirements}

The SCIC items are designed to allow inspection, maintenance, and testing to ensure their continued functioning, readiness for operation, and accuracy. The surveillance system design incorporates features for verifying system operability status and component states (e.g., run status, error status, and system alarms).

NOTE: All test circuits and status lights do not perform an active safety function and are therefore, not required to be fail-safe.

The system reliability, availability, and maintainability goal is 98 percent. Routine repair maintenance is not anticipated during the life of the system, which is five years. Items that may require replacement or repair are accessible and readily changed (i.e., relays).

- All replacement and spare parts have either the same manufacturer and model number as the original or are engineering-approved equivalents. Since a number of components are procured as Commercial Grade (CG) a dedication process is invoked to assure that the function of the device will meet safety class performance criteria. Replacement parts must undergo this Commercial Grade Item (CGI) dedication process. This process is a spent nuclear fuel administrative process outside the scope of this SDD. 


\subsection{Other Requirements}

Each major component has a securely fastened nameplate (stainless steel or laminated plastic) with the manufacturer's name model and serial number indicated.

1. Requirement: Recovery from automatic initiations shall be as follows:

- $\quad$ Recovery from an SCHe purge and isolation shall be manually initiated in the respective bay. Control logic shall reset automatically; however, the final output logic will require a local manual reset. Recovery from an $\mathrm{SCHe}$ purge and isolation shall ensure that a purge of at least $1 / 2$ hour has occurred to ensure that $\mathrm{MCO}$ oxygen concentrations are at nonflamable levels before the SCHe purge is stopped.

- Recovery from a seismic trip shall require manual reset at the location of the seismic actuation logic train A and B. Auctioneering of three units $(2 / 3$ logic) may be utilized.

- Recovery from high heat input trips shall be in the respective bays. Control logic shall reset automatically; however, the final output logic will require manual local reset.

Basis: These requirements are established to provide for a controlled return to normal operations, and are consistent with best operating practices.

How the system meets the requirement: The system is designed for manual resets as described in Section 4.0.

2. Requirement: The following operational support requirements shall be met:

- The control logic and instruments shall be powered from facility non-safety power. Analysis or testing must be performed to ensure this non-safety power cannot affect the safety-class features being performed. See DOE Order 6430.1A for specific guidance. UPS power shall not be used for the trip functions to insure a SCIC trip on loss of facility power. The SCIC Annunciator does not provide a trip function but does require a UPS.

- The system shall be designed to isolate and purge the MCO and shutdown the TW Heater and pump on loss of facility electrical power (fail-safe).

- Electrical isolation shall be provided to separate the safety class system from this non-safety system. This would include all interfacing with the MCS and the non-safety power source.

Basis: These requirements are consistent with standard operating practices for safety systems. 
How the system meets the requirement: The design of the system is for fail safe mode under loss of power. UPS power is supplied as a defense-in-depth measure.

3. Requirement: All equipment required to perform the SCIC safety functions shall be seismically qualified to Performance Category 3 criteria to perform its safety function following a design basis seismic event.

- $\quad$ Seismically qualified final relays in the safety-class logic shall be used. With this control scheme in mind, isolated signals from the MCS shall be able to control the open and close position of any of the $\mathrm{MCO}$ isolation valves, provided the $\mathrm{SCHe}$ has not been initiated. A possible scheme for this is to have the safety-class logic feed these relays in series with the MCS isolated contact. In no case shall the MCS or any other non-safety system prevent the activation of the SCHe system and isolation.

- In the case of CVDF control room annunciator, there is no requirement to meet PC-3 or PC-2 seismic design criteria. The use of seismic monitors eliminates the need to seismically qualify the safety-class instruments and electronics as long as a seismically qualified seal-in function is provided.

Basis: DOE-STD-1020, and results of the Final Safety Analysis Report, HNF-3553, Annex B.

How the system meets the requirement: All SCIC equipment have been qualified to Performance Category 3 criteria except for the control room annunciators.

\subsubsection{Security and Special Nuclear Material Protection}

There are no security and SNM protection requirements associated with this system.

\subsubsection{Special Installation Requirements}

The main safety-class cabinets are bolted to the process bay floor to meet performance category 3 seismic requirements and the smaller cabinets and starters are mounted on stands, which are mounted to the process bay floor. The SCIC system control room annunciators are floormounted and meet performance category 1 seismic requirements. All safety-class conduit must meet the anchorage requirements specified in Section 3.3.1.

\subsubsection{Reliability, Availability, and Preferred Failure Modes}

The SCIC system requires that each process bay be monitored by two SCIC system PLCs that are capable of independent action. All critical signals are through redundant transmitters or switches and all critical shutoffs are provided by at least two independent isolation valves. These valves are designed to assume a safe (isolated) position in the event of loss of power. Each process line into the $\mathrm{MCO}$ has two in-line isolation valves, and when either of these valves close, adequate isolation is provided. One valve is aligned with Train A and the other with Train B of the SCIC. 
A limitation of having two separate trains (A and B) is that the mode switch could be misaligned so that the trip protection for one train is incorrect. The positioning of the MODE switch is administratively controlled through the SAR technical safety requirements (TSRs). Misalignment or failure would result in non-safety alarms and process stoppage from the MCS software interlocks.

The TW trip is accomplished through the use of two redundant sensors high temperature switches (TSHs) and two independent logic trains. Only one train is required to perform the safety function to stop heat input into the $\mathrm{MCO}$.

SCHe system supply of helium to the $\mathrm{MCO}$ is accomplished by two separate supply systems on each process connection into the MCO. These four lines have an isolation valve, which is powered by either Train A or Train B of the SCIC system. These valves are designed to open on failure or loss of power. At least one valve on each side must function to initiate a purge and repressurization of the $\mathrm{MCO}$.

The PWC seismic trip protection is not redundant, unlike all other SCIC portions. Instead, Train A of the Seismic trip circuit feeds the starter for one of the PWC pumps (PWC-P-4035) and Train B feeds the starter for the other PWC pump (PWC-P-4036). This protection is Defense-InDepth and does not require the same level of protection. In addition, it would take a combination of seismic-induced pipe failures while retaining power to the pumps and a loss of power to the HVAC fans, which is considered very unlikely. This level of protection is considered adequate for this unlikely event sequence.

3.5.3.1 Summary of Potential System and Component Failure. Failure of a SCIC system PLC: loss of system redundancy response to safety-class events remains unchanged due to independent action of the second SCIC system PLC, or failed SCIC system PLC causes safe shutdown of process. PLCs have internal diagnostic program running at all times; a PLC fault will result in an MCO ISO \& PURGE.

Failure of pressure transmitter to activate trip: loss of system redundancy: Response to safetyclass event remains unchanged due to independent signal from second transmitter.

Failure of pressure transmitter that activates trip: safe shutdown of process: Process placed in safe condition by trip function.

Failure of temperature switch to activate trip: loss of system redundancy. Response to safetyclass event remains unchanged due to independent signal from second switch.

Failure of level switch to activate alarm: loss of system redundancy. Annunciation is provided by independent, redundant signal from second switch.

Failure of level switch, which activates alarm: operator verifies level and initiates corrective action. 
Failure of flow transmitter to activate trip: loss of system redundancy. Response to safety-class event remains unchanged due to independent signal from second transmitter and PLC.

Failure of flow transmitter, which activates trip: safe shutdown of process. Process placed in safe condition by trip function.

Failure of seismic monitor to activate trip: loss of system redundancy. Response to safety-class event remains unchanged due to independent signals from remaining two sensors.

Failure of single seismic monitor: causes non-safety alarm but does not cause a trip until second of three sensors are in trip condition.

A major seismic event trips all three seismic monitors causing both an MCO ISO \& PURGE and a TW trip. The control room functions, both the mode switch and annunciation, may not be available since the control room is not seismically qualified. There are no control room functions required during or after a seismic event. The switches and transmitters used as inputs to the SCIC are also not seismically-qualified for operability since none are needed for postaccident indication or control and the seismic monitoring portion of the SCIC places the process system in a safe-shutdown mode.

Failure of one of the two seismic trip circuits may prevent the PWC pump from being deenergized. However, the circuits are fail-safe and would normally fail open to serve its DefenseIn-Depth function. Again, it is unlikely that the conditions that would support an unmitigated release from a PWC spray leak could ever occur. The protection is considered adequate.

\subsubsection{Quality Assurance}

The SCIC system quality assurance/control program is based on the safety classifications of the SSCs as detailed in the Safety Equipment List (HNF-SD-SNF-SEL-002) and application of a graded approach as described in the Project Hanford Quality Assurance Program Description (HNF-MP-599).

\subsubsection{Miscellaneous Requirements}

3.5.5.1 Margins of Safety. All safety-class instrument setpoints are calculated per ANSI/ISA S67.04, Setpoints for Nuclear Safety Related Instrumentation. This ensures that the trip point is adjusted, in the conservative direction, to assure the proper response. Total instrument error is formulated by evaluating drift, calibration frequency, ability to set the device (setpoint calibration), and environmental conditions (temperature, pressure, humidity, etc.). These components are all considered in the setpoint calculation (SNF-4451).

The setpoint values listed in the next section indicate the parameter limit of the particular trip and the SCIC trip setpoint, which accounts for total instrument error. The parameter limit values are identified in the CVDF SAR and are not the responsibility of the SCIC. For example, the $50^{\circ} \mathrm{C} \mathrm{TW}$ parameter limit is listed, then the SCIC trip setpoint is listed. The total instrument error for the temperature switch high (TSH) is also listed. Table 4-3 shows all parameter limits and SCIC trip points. 


\subsection{SYSTEM DESCRIPTION}

\subsection{Configuration}

\subsubsection{Description of System, Subsystems, and Major Components}

The SCIC system provides safety sensing, actuation logic, actuation signals, and control interfaces to prevent a $\mathrm{MCO}$ fuel thermal runaway reaction over temperature and $\mathrm{MCO}$ highpressure blowdown and hydrogen explosion within the MCO. The SCIC system includes all of the equipment, actuation logic, electrical cabinets, conduits and wiring, local status indication and remote alarms, and controls for system operation and testing. With the exception of the seismic monitoring equipment, all field instruments (flow, pressure, temperature switches) are provided by the VPS and the GSHe system (System 13-1). Additional Defense-In-Depth protection is also provided as part of the SCIC, including protection from external hydrogen explosion and spray leak accidents.

The SCIC system consists of three portions: the MCO ISO \& PURGE, the TW over-temperature trip, and the seismic detection and trip circuits.

The following functions are provided by the SCIC:

- $\quad$ Local bay SCIC system isolation and purge activation switches, ISO \& PURGE

- $\quad$ Seven position process mode control switches are provided in the CVDF control room for both Trains A and B. The modes are 1. BYPASS, 2. HEATUP, 3. DRAIN, 4. PURGE/FLUSH, 5. DRYING, 6. PROOF, and 7. PRESSURE TEST.

- $\quad$ Status lights for various signal conditions, including TW high temperature trip, seismic trip, cask annulus water level low, and bay high temperature.

- $\quad$ Logic test and reset switches

4.1.1.1 MCO ISO \& Purge. For the MCO ISO \& PURGE, the SCIC receives signals for MCO pressure (both positive pressure and vacuum), helium flow rate, bay high temperature switches, seismic trips, and time under vacuum trips. This is the major portion of the SCIC system that contains the four PLCS, relay logic, and operator interface switches needed to perform the safety functions. The PLCs contain signal-input cards, which receive all pressure and flow signals used by the SCIC. The eight MCO isolation valves, i.e. energized (open) or deenergized (closed), and four SCHe isolation valves, i.e. energized (closed) or de-energized (open), are controlled by the SCIC through relay output contacts. Another important part of the logic, is the process MODE switches. These switches have seven positions, which are positioned by the operator throughout the process from heat-up through pressure test. Each logic trip is enabled or disabled by this switch. The seismic and TW trips are hardwired and are independent of the PLC logic trips and the mode switch. 
Two local panels are used to access Train A and Train B for each of the four process bays. These panels give the status of the safety system and allow the operator to initiate logic and interlock tests or an ISO \& PURGE, and to reset the TW and ISO \& PURGE trips. Using two separate racks of equipment; wiring, conduit and independence between Train $\mathrm{A}$ and Train $\mathrm{B}$ provides redundancy and physical separation. The use of a single PLC in bay 2 to provide the logic control of bay 2 and 3 was based upon the need to reduce the number of safety-class PLCs and software. Although Train B's PLC is physically separated buy its location in bay 3 , all bay 2 inputs are still routed through the panel in bay 2 . The PLC in process bay 2 provides logic to Train A for process bays 2 and 3. The controller in process bay 3 provides logic to Train B for process bays 2 and 3. A similar arrangement is used for process bays 4 and 5 . During the CVD processing of an $\mathrm{MCO}$, the SCIC system is placed into the mode appropriate for the processing stage. Each of the modes allows the SCIC system to monitor different sensors with setpoints and logic appropriate for that processing step.

The SCIC system isolates the MCO and initiates a SCHe system purge if any of the following occur:

- Loss of power (fail-safe condition).

- Manually-initiated safety-class isolation and SCHe purge from one of the SCIC ISO \& PURGE buttons (administratively-controlled).

- Exceeding eight hours at vacuum during the first vacuum cycle or four hours of vacuum during all subsequent vacuum cycles without re-pressurizing the MCO for a minimum of four hours. This is referred to as the $8 / 4 / 4$ requirement and provides thermal reset within the MCO.

- $\quad$ MCO below atmospheric pressure and the helium flow below the minimum required to keep hydrogen less than 4 percent by volume. When MCO pressure is below 12 torr, there is insufficient hydrogen to exceed the 4 percent level and no purge is required. A five-minute time delay on low-flow allows flow to be stopped in order to reach $<12$ torr [ 8 torr] . In addition, after the 12 torr is achieved, a two-minute delay is provided to reestablish normal flow without a false trip condition.

- $\quad$ MCO above the high-pressure setpoint.

- The transition from above atmosphere $0.76 \mathrm{psig}[0.5 \mathrm{psig}]$ to vacuum, time to reach less than -11.7 psig ( 155 torr) exceeds five minutes.

- The transition from below $-11.1 \mathrm{psig}(\sim 185$ torr) back to greater than 0.5 psig pressure exceeds five minutes.

- $\quad$ MCO reaches an incorrect pressure state without adequate, verified purge volume. The MCO must be maintained above a positive pressure (approximately $0.5 \mathrm{psig}$ ) to prevent oxygen ingress unless a purge of adequate volume has been completed. During bulk 
water draining and the subsequence rinse, the $\mathrm{MCO}$ must remain above atmospheric pressure.

- Bay temperature exceeds the high-temperature parameter limit of $105^{\circ} \mathrm{F}$, which impacts safety-class instrument calibration.

- $\quad$ Seismic event of sufficient magnitude (below UBC levels).

4.1.1.2 Tempered Water. The following field sensor (Trains A and B) are inputs to the TW trip. These temperature switches provide closed contacts that open on high temperature.

Table 4-1. Sensor Inputs for the TW Trip

\begin{tabular}{|c|l|l|l|l|}
\hline Channel & Bay 2 & \multicolumn{1}{|c|}{ Bay 3 } & Bay 4 & Bay 5 \\
\hline A & TSH 1228 & TSH 1328 & TSH 1428 & TSH 1528 \\
\hline B & TSH 1229 & TSH 1329 & TSH 1429 & TSH 1529 \\
\hline
\end{tabular}

The TW TSH contacts (both Channels A and B) provide four separate starter panels that provide 480-VAC power to the TW pump and heater. Should either Train A or B contact open, both heater and pump starters open to stop heat from being added to the TW system. There are two safety-class starters in series with the power to the pump as well as two starters in series with the heater.

The TW TSHs are not seismically-qualified though over-temperature protection is required after a DBE. The seismic monitoring portion of the SCIC provides this protection by tripping the TW high-temperature protection circuit during a low-level seismic event.

Upon activation of TW high-temperature protection, the SCIC contacts remain open until all the following have occurred:

a. The TSH is reset due to process temperature reduction (contact closed).

b. The seismic trip (if a trip occurred) is reset in Bay 1 .

c. The SCIC trip circuit is manually reset in the respective bay.

The test switches mimic an actual temperature trip as close as possible to provide testing of the trip circuit. By actuating the test, the TW heater and pump starters open. A key lock switch is provided to prevent inadvertent actuation of a trip condition using test switches.

TW HI TEMP and SEISMIC TRIP status indicators are provided in the respective bays. These indicators are normally illuminated green when there is no trip. Upon a trip condition, the 
indicator extinguishes and stays extinguished until the condition has been reset, as described above. Lamp tests are provided.

4.1.1.3 Seismic Monitoring. Seismic recorders are used to detect, record, and trip during a seismic event that exceeds $0.05 \mathrm{~g}$. triaxial any direction. There are three seismic sensors/recorder: one each in bays 2,3 , and 4 . The two seismic logic and relay panels are located in bay 1 to provide easy access for Operations and Maintenance.

To reduce spurious trips, the three sensors are auctioneered ( $2 / 3$ logic) with self-resetting trips from each sensor. Reset of a single sensor trip occurs in approximately 30 seconds from the time of the last seismic level above $0.5 \mathrm{~g}$. If at least two of the three sensors alarm, a seismic trip occurs. A seismic trip de-energizes the TW heater and circulation pump, initiates an automatic ISO \& PURGE of the MCO, and de-energizes the PWC circulating pumps. In addition, seismic alarms are sent to the MCS.

All seismic equipment receives $120 \mathrm{VAC}$ from a non-safety source. The seismic sensor/recorders include battery backup power so seismic monitoring can continue during a power outage to record seismic activity during/after an earthquake for analysis of the potential impacts of the earthquake. The battery is not required to function to provide the safety feature of the seismic monitor. Instead, a loss of power initiates a trip (i.e. fail safe).

RS-485 multi-drop communication, as defined by the Telecommunication Industry Association (TIA) in TIA/EIS-485, is provided between the seismic recorders (sensors) and one of the logic and relay panels. A RS-485 PC card in a laptop allows communication to and from all three recorders for analysis, calibration checks, and setpoint changes.

Reset after a seismic $2 / 3$ trip requires a manual reset in bay 1 for both Trains $A$ and $B$.

The seismic monitoring system components and wiring are fail-safe, whereas failures result in both an alarm and a trip signal (i.e., relays normally energized, contacts closed).

The seismic monitoring sensor alarms [Units 1,2, and 3; seismic 2/3 trips; and error alarm (Channels A and B)] are provided to the non-safety MCS.

4.1.1.4 SC Alarm Annunciation. Safety-class cask annulus low-level alarms are provided in the CVDF control room. Electrical contacts are provided from the field by the two Level Switch Low (LSL) sensors in bays 2 through 5 . These inputs open on low-water level for an alarm condition. A loss of signal (wire break) also generates an alarm in the control room (fail-safe).

Low level alarms have a bypass feature that disables the alarm during process inactivity. This inactivity occurs at three stages of the MCO drying process: upon receipt before the TW system is connected, after drying is complete and the annulus water is drained, and when there is no $\mathrm{MCO}$ in the bay. This feature is key-protected to provide better control of its position.

The following 12 alarms (three alarms in each of the four bays) are provided on the safety-class annunciators. 
BAY * ISOLATION \& PURGE
BAY * ANNULUS LOW LEVEL
BAY * PWC LOW FLOW
Where * $=2,3,4$, and 5 for bays 2 through 5

NOTE: The BAY * PWC LOW FLOW alarm serves to monitor and alarm the PWC pre-drain purge and post-drain purge to aid in the prevention of explosive levels of hydrogen and oxygen in the PWC receiving tanks. Manual operator action is required upon an alarm. This alarm function is Defense-In-Depth.

NOTE: The control room safety-class annunciator is required for non-seismic events only. During a seismic event, the SCIC system isolates and purges the MCO with no required operator action. Because all safety-class piping is seismically qualified, no line breaks can occur within the safety-class isolation boundary. After a timed purge, based on bottle capacity, a pressure blanket is maintained on the $\mathrm{MCO}$ for at least 96 hours, guaranteeing adequate operator response time.

Individual bay manual BAY * ISO\&PURGE INITIATE push buttons are provided on the safetyclass annunciator panels. These eight buttons, two each for bays 2 through 5 (Trains $A$ and $B$ ) provide protection for inadvertent actuation. Either Train A or B ISO \& PURGE button initiates a safety-class isolation and a SCHe purge in the selected bay, though only half the MCO isolation valves close and half the SCHe valves open. It is intended that both Trains A and B push buttons are pushed to initiate a trip.

The safety-class annunciator panels provide lamp/circuit tests for all annunciator cards and lamps. The horn sounds upon testing.

The alarms sequence is automatically reset as follows

- blinking light and horn on receipt of alarm,

- $\quad$ solid light, horn silent when acknowledged (alarm condition still in),

- $\quad$ self-clearing light when the condition clears (once acknowledged).

This sequence ensures that momentary alarms are captured and new alarms are discernable from existing alarms.

4.1.1.5 Non-Safety Interfaces. Trip and alarm parameters are provided to the facility MCS for non-safety display and control functions. The MCS is a non-safety, PLC-based system, therefore non-safety signals to or from the MCS are isolated from the SCIC safety signals. Signals produced in bays 2 through 5 are connected to the local MCS cabinet for connections. There are three signal types: contacts, analog voltages, and RS-485 communications. The RS484 multi-drop communication provides a multitude of signals from the PLC software trip logic. 


\subsubsection{Boundaries and Interfaces}

Aside from seismic sensors, there are four separate SCIC panel sets for each process bay (Train $\mathrm{A}$ and Train B). All safety-class equipment that requires seismic qualification to guarantee function after a performance category 2 or 3 seismic event is located in process bays 1 through 5 . There are three seismic monitors (one each in bay $2,3,4$ ) to support $2 / 3$ logic. The seismic monitoring auctioneering control panels are located in process bay 1 to provide easy access for alarm response and maintenance. Other equipment, specifically operator interface panels and the annunciators, is located in the control room.

Sensors and transmitters providing input to the SCIC system consist of the following (refer to Figure 3-1):

- $\quad \mathrm{MCO}$ vacuum pressure (12 torr): PT-1*08 (A) and PT-1*10 (B) (vacuum levels)

- $\mathrm{MCO}$ above atmospheric pressure, $\mathrm{MCO}$ high pressure or high vacuum pressure: $\mathrm{PT}$ $1 * 36(\mathrm{~A}), \mathrm{PT}-1 * 37(\mathrm{~B})$

- Normal and high helium purge rates: FIT- $1 * 20(\mathrm{~A})$ and FIT-1*21 (B)

- $\quad$ Cask/MCO annulus water low-level switch: LSL-1*24 (A), LSL-1*25 (B)

- TW (annulus) system high-temperature switch: TSH $-1 * 28$ (A) and TSH $-1 * 29$ (B).

Note: Although the TSH comes with dual contacts, which allows for two different setpoints, only one contact is used. Unlike the process bay high temperature switch, there is no room for setting a warning alarm between the normal operating temperature and the trip point.

- $\quad$ Process bay high-temperature switch: TSH/TSHH-1*38 (A) and TSH/TSHH-1*39 (B) (NOTE: TSH outputs are used for a warning alarm to the MCS and are electrically routed and isolated via the SCIC panels to the MCS.).

- $\quad$ Seismic trip sensors (ATR-5235, ATR-5336, and ATR-5437), auctioneering circuitry (CP-120 and CP121) and seismic buffer panels (CP 122 and CP 123).

NOTE: Inputs from SCIC system seismic monitors provide indication of a safety-class seismic event. However, the seismic trips are independent of safety-class logic. The seismic trip directly controls the final output relay, which is either closed to allow power to the MCO isolation valves, TW heater, TW pump, and PWC pump starters, or opened on a trip or loss of power. Once a seismic trip is activated, all other logic is circumvented and no longer has a safety-class function. 
The SCIC system interfaces with the following safety-class MCO isolation valves (refer to Figure 3-1):

- MCO drain: PWC- GOV-1*03 (A) and PWC-GOV-1*30 (B)

- Vacuum system: VPS-GOV-1*05 (A), VPS-GOV-1*09 (B)

- Vacuum system: VPS-GOV-1*11 (A), VPS-GOV-1*17 (B)

- Process helium: He-GOV-1*06 (A) and He-GOV-1*02 (B)

- $\quad \mathrm{SCHe}$ system purge long dip tube side: SCHe-GOV-5*12 (A) and SCHe-GOV-5*31 (B)

- $\quad \mathrm{SCHe}$ system purge short dip tube side: SCHe-GOV-5*51 (A), and SCHe-GOV-5*71 (B).

\subsubsection{Physical Location and Layout}

- The majority of the SCIC system is located in the four active process bays (bays 2 through 5), to benefit from the bays' seismic qualification. Required routine access during normal processing is minimized as bay entry requirements is limited .

- The seismic recorders (sensors 1,2, and 3) are located in bays 2, 3, and 4, respectively. The seismic logic and relay panels are located in bay 1 .

- The safety-class annunciators and SCIC mode initiation panels are located in the CVDF control room.

\subsubsection{Principles of Operation}

The SCIC system's primary function is to monitor process parameters and respond to values outside the setpoint allowances to protect the environment, on-site workers, and other safetyclass components. The concept used in the design is that the SCIC would never trip unless there was an equipment failure. The MCS controls the process within the normal operating ranges without exceeding the SCIC trip points.

Section 4.1.6.4 provides the details of the trips provided by the SCIC.

Depending on the mode, the SCIC PLC performs various setpoint comparisons and provides safety-related timing functions. The vacuum timer monitors the time under vacuum to limit heat-up of the fuel as conduction from the fuel to the MCO is reduced. After the vacuum cycle, a minimum time above atmosphere pressure is required to cool down the fuel. Exceeding the time under vacuum or returning to vacuum without first meeting the minimum time at pressure will result in $\mathrm{MCO}$ isolation and $\mathrm{SCHe}$ system purge. 
Alarms for all four process bays are displayed in the CVDF control room using two independent annunciator panels, Trains A and B. The operator can manually initiate a helium purge for each of the process bay from these panels. There are two safety-class alarms provided to the CVDF control room, BAY ANNULUS LOW LEVEL and BAY ISOLATION \& PURGE. The control room safety-class annunciator is required for non-seismic events only. During a seismic event, the SCIC system places the system in a "safe" mode that isolates and purges the MCO with no required operator action. Because all safety-class piping are seismically-qualified, no line breaks can occur within the safety-class isolation boundary. After a timed purge, based on bottle capacity, a pressure blanket is maintained on the MCO for at least 96 hours, guaranteeing adequate operator response time.

The SCIC system provides non-safety-class signals to the facility MCS and the PWC seismic pump shutdown starters. During normal process operations, the SCIC system allows signals from the facility control system to operate all of the isolation valves except the SCHe system valves. These signals and their wiring and conduit do not fall within the system boundary. During AC power loss, the system moves to a fail-safe condition by closing all isolation valves around the $\mathrm{MCO}$ and opening the SCHe system purge valves. For this reason, the incoming nonsafety AC power supply is not part of the SCIC system boundary.

\subsubsection{System Reliability}

The SCIC system requires that two SCIC safety-class trains monitor each process bay. This includes the portion that contains the MCO ISO \& PURGE trip, the TW trip, and the seismic monitoring trip. Each have two independent systems that are capable of independent action to perform their respective safety feature. All signals are through redundant transmitters or switches and all critical shutoffs are provided by at least two independent isolation valves for the ISO \& PURGE trip, and two independent starters for the TW heater and pump components (heater and pump) for the TW trip. The valves and TW pump and heater are designed to fail safe in the event of loss of power or, in the case of the isolation valves, loss of instrument air. The PWC seismic trip circuit does not have redundancy as this feature is Defense-In-Depth.

SCHe system purge is accomplished by two separate supply systems with two parallel purge valves in each system. These valves are designed to open on failure or loss of power.

\subsubsection{System Control Features}

4.1.6.1 System Monitoring. Bay isolation and purge alarms, TW (annulus) bay low level alarms and non-safety PWC bay purge low are annunciated and displayed on the control room annunciator panels.

In addition to the control room alarms, lights on each of the local operator panels indicate the following statuses: ISO \& PURGE, SEISMIC, TW HIGH TEMPERATURE, BAY TEMPERATURE trip, and ANNULUS LOW LEVEL alarm. 


\subsubsection{Control Capability and Locations}

- Normal Operations. During normal operations, the operator selects the SCIC system mode from the mode selection key switches (HS-6707, HS-6708, HS-6709, and HS-6710 for Train A and HS-6807, HS-6808, HS-6809, and HS-6810 for Train B) located on the two operator panels (CP-607 for Train A, CP-608 for Train B) in the CVDF control room

- Reset After a Trip. The operator pushes the appropriate reset buttons on the two local operator panels located in each bay to reset the system after an alarm trip. After a high TW (annulus) trip, HS-*007, HS-*107 resets the system, and following an isolation and purge, Trains A and B are reset by HS-*006, HS-*106, respectively. Reset is only possible if the parameter has returned to below the trip point, with the exception of low flow, which is zero during the isolation of the $\mathrm{MCO}$. For the seismic monitoring circuits, trip reset is performed in bay 1 on the two auctioneering panels.

- Trip Tests. Each local operator panel has the ability to simulate selected event trips to test the logic. The test is enabled by a key switch (HS-*001, HS-*101) on the panel. Once enabled, the TW HIGH TEMPERATURE, BAY HIGH TEMPERATURE, and ANNULUS LOW LEVEL can be simulated by pressing the appropriate button.

4.1.6.3 Automatic and Manual Actions. The SCIC is an automatic system that trips the TW heater and pump starters if the temperature setpoint is exceeded or a seismic event above the setpoint has occurred. Other trips and interlocks are automatic but dependent upon the position of the mode control switches. Alarms are also automatic but require operator action to acknowledge the alarm and to respond to the event. A manual initiation of an MCO ISO \& PURGE trip can be performed in each bay for that bay or in the control room for any bay. The original purpose of the control room shutdown switches is to allow the operator to initiate a trip during site emergencies that may require evacuation of the control room. There is no requirement for the operator in the control room to monitor system parameters or to initiate a safety-class trip since the SCIC performs this function automatically. For conduct of operations, this feature provides a level of convenience and would be prudent for external emergencies.

\subsubsection{Setpoints}

4.1.6.4.1 Trip Setpoints. The first three trips listed below (seismic, high TW temp, and hi bay temp) are non-PLC trips since the PLC does not provide logic to control these trips. The remaining trips use a combination of PLC logic and hardwired relay logic to arrive at their trip function. See Table 4-2. 
SNF-3091 REV 0

Table 4-2. SCIC Trip Setpoints, Instrument Error, and Delay Times (2 Sheets)

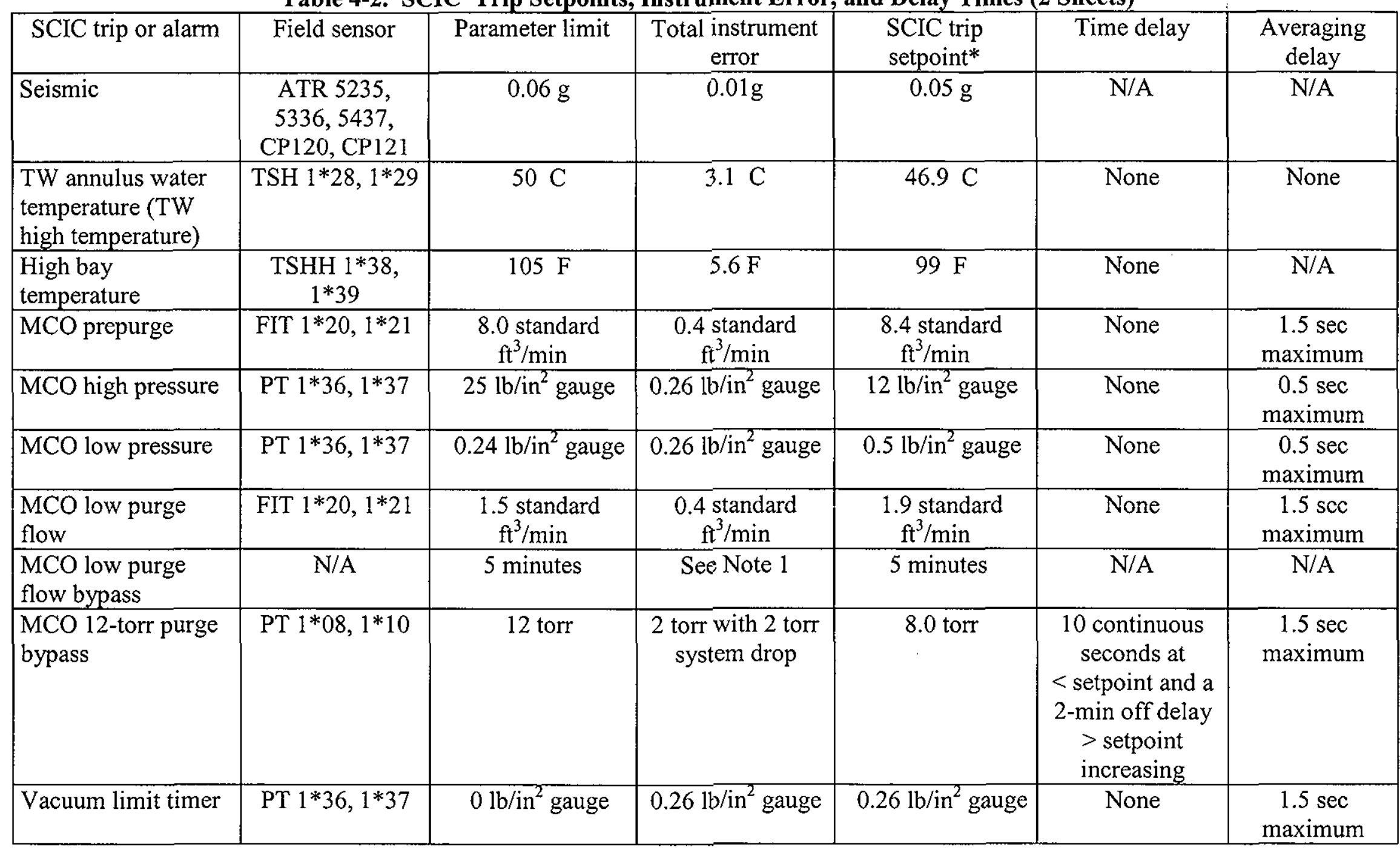


SNF-3091 REV 0

\begin{tabular}{|c|c|c|c|c|c|c|}
\hline Vacuum limit timer & N/A & $8-4-4$ hours & See Note 1 & $8-4-4$ hours & None & N/A \\
\hline $\begin{array}{l}\text { MCO pressure } \\
\text { decay fail }\end{array}$ & PT $1 * 36,1 * 37$ & $\begin{array}{c}0.24 \mathrm{lb} / \mathrm{in}^{2} \text { gauge } \\
\text { and }-11.4 \mathrm{lb} / \mathrm{in}^{2} \\
\text { gauge }\end{array}$ & $\begin{array}{c}0.26 \mathrm{lb} / \mathrm{in}^{2} \text { gauge } \\
\text { and } 0.3 \mathrm{lb} / \mathrm{in}^{2} \\
\text { gauge }\end{array}$ & $\begin{array}{l}0.5 \mathrm{lb} / \mathrm{in}^{2} \text { gauge } \\
\text { and }-11.7 \mathrm{lb} / \mathrm{in}^{2} \\
\text { gauge }\end{array}$ & $\begin{array}{c}5 \text { continuous } \\
\text { seconds }<0.5 \\
\mathrm{lb} / \mathrm{in}^{2} \text { gauge, } \\
\text { no delay on } \\
\text { reaching }-11.7 \\
\mathrm{lb} / \mathrm{in}^{2} \text { gauge }\end{array}$ & $\begin{array}{c}1.5 \mathrm{sec} \\
\text { maximum }\end{array}$ \\
\hline $\begin{array}{l}\text { Bay annulus water } \\
\text { low-level alarm }\end{array}$ & LSL $1 * 24,1 * 25$ & $10 \%$ of gauge & See Note 2 & $20 \%$ of gauge & None & None \\
\hline
\end{tabular}

Notes:

1. Time functions are not prone to errors in setpoint, therefore no error is applied. The safety limit and the SCIC sctpoint are equal.

2. Bay annulus water level gauge and level switch are at least $1 \mathrm{ft}$ above the level of the fuel and therefore the level setpoint is well above the required safety limit.

*SNF-4451, 1999, Cold Vacuum Drying (CVD) Set Point Determination, Rev. 0, Fluor Danicl Hanford, Incorporated, Richland, Washington. 
The values listed below indicate the parameter limit of the particular trip and the SCIC trip setpoint, which accounts for total instrument error. For example, the $50^{\circ} \mathrm{C} \mathrm{TW}$ parameter limit is listed with the SCIC trip setpoint of $46.9^{\circ} \mathrm{C}$ listed in brackets. The total instrument error for the TSH is calculated to be $3.1^{\circ} \mathrm{C}$. See also Section 3.5.5.1.

All analog signals coming from pressure and flow are averaged to remove fluctuations that may occur due to instrument spikes. Since the safety-class PLC sample time is no greater than 100 milliseconds (ms), the longest delay for a five-sample average is 0.5 seconds and for a 15 -sample average, the longest delay is 1.5 seconds. Refer to the discussion below for the number of samples used:

\section{Seismic Monitoring Trip}

The seismic monitoring trip design was based on reducing the seismic qualification necessary for all instruments used by the SCIC for trip functions and to allow the Mode Switch to be located in a non-seismically-qualified location (CVDF control room). The $0.05 \mathrm{~g}$ value was selected to assure a seismic trip well in advance of a seismic event of significant magnitude to break the piping that is not part of the qualified primary $\mathrm{MCO}$ boundary. This feature allows all the piping outside the isolation valves to be general service, which reduces costs (initial and lifetime) and supports the schedule for moving fuel from the K-Basins. There was no credit for "catching" a seismic event buildup from low to high levels. It was considered that a large magnitude (below DBE) could occur without a time lag between the 0.05 and the $0.26 \mathrm{DBE}$ level. In this scenario, some oxygen ingress or MCO depressurization is likely, depending on the mode. The system of initiating the SCHe purge accounts for either of these two accidents. The $0.05 \mathrm{~g}$ level is at a point where most people would feel the effect but no damage would occur. This level is $\sim 20$ percent of the DBE level of $0.26 \mathrm{~g}$.

\section{TW High Temperature Trip}

The TW high-temperature trip is an interlock on the TW heater and pump if temperature reaches $50^{\circ} \mathrm{C}\left[46.1^{\circ} \mathrm{C}\right]$. All the logic associated with this trip is through hardwired relays. The safety function is to prevent a thermal runaway of the MCO fuel by limiting the heat input into the cask, which transfers its heat into the MCO gas or water to the fuel. Since all thermal analysis was based on the $50^{\circ} \mathrm{C}$ value, the SCIC must activate below this limit. Once the heater is deenergized (breaker open) and the function of the trip is met, re-establishing flow may be permissible to allow for more rapid cooldown for operations.

\section{High Bay Temperature Trip}

The bay temperature trip serves to limit the effects of temperature on the two vacuum pressure transmitters, PT $1 * 08$ and PT $1 * 10$. These devices have a calibration limit of $105^{\circ} \mathrm{F}$, which sets the parameter limit. The thermal stability of the MCO under helium pressure with stagnant TW has been demonstrated at a bay temperature of $115^{\circ} \mathrm{F}$. The two temperature switches are located on the hood assembly (part of the VPS). This location is considered appropriate since all safetyclass instruments are situated in this same location. 


\section{MCO Pre-Purge Trip}

The MCO pre-purge trip detects a low purge flow rate or inadequate purge time prior to pulling a vacuum in the MCO. The MCO low-pressure trip is active and the MCO pre-purge bypasses this trip if the MCO purge is complete. This trip ensures that the gas in the MCO is below the lower flammability limit (LFL) for hydrogen prior to going to vacuum. In the event of an undetected leak, oxygen could be introduced upon entering the vacuum mode.

A continuous purge rate of $>8.4 \mathrm{scfm}$, as read on FIT $1 * 20$ (Train A) and FIT $1 * 21$ (Train B), must be met for at least 15 minutes to bypass the $\mathrm{MCO}$ low pressure trip and allow vacuum operation without an ISO \& PURGE trip. Once this bypass is set, the contact only opens when MCO pressure is $>0.5$ psig increasing ( 5 second delay) as read on PT $1 * 36$ (Train A) and PT $1 * 37$ (Train B). A 15-sample average of the flow signal is used.

\section{MCO Low-Pressure Trip}

The MCO low-pressure trip is used during draining and purge/rinse modes to assure a limited amount of air ingress into the MCO. These two modes require that the MCO be pressurized at all time so that even with a major line break, the combination of oxygen in-leakage and hydrogen will not create an explosive environment. In the drying and proof modes, the system is cycled between pressure and vacuum, which keeps hydrogen at low concentrations when entering vacuum. This is accomplished with the MCO pre-purge as indicated above.

The pressure trip logic is "true" if the MCO pressure from PT- $1 * 36$ (Train A) or PT $1 * 37$ (Train B) drops below $0.5 \mathrm{psig}$. The MCO Low-Pressure trip relay contact opens on low pressure. Condition reset occurs when pressure is above $\sim 0.5 \mathrm{psig}$.

Timing from detection of a low pressure and response to $\mathrm{SCHe}$ valves opening is critical to maintaining a non-explosive mixture of hydrogen and oxygen in the $\mathrm{MCO}$. A five-sample average is used to reduce the potential for spurious trips and is limited to 0.5 seconds due to the response time requirements. Expected response time is 0.5 seconds from the parameter limit of $0.0 .24 \mathrm{psig}$ (SCIC uses $0.5 \mathrm{psig}$ - instrument error), 0.2 second delay due to SCIC actuation logic, and a one-second delay to open the SCHe valves. Total delay to trip from $0.24 \mathrm{psig}$ is $\sim 1.7$ seconds. During leaks, not major line breaks, this timing prevents any in-leakage of air. For major line faults, some air may enter the MCO but is limited to preclude an explosive mixture of air and hydrogen

\section{MCO High-Pressure Trip}

The MCO High-Pressure trip is used during all processing modes except 1 Bypass, 2 Heatup, and 7 Pressure Test, to ensure that a high MCO pressure does not occur if the MCO is isolated without the SCHe vent path. 
The pressure trip is true if the MCO pressure from PT- $1 * 36$ (Train A) or PT $1 * 37$ (Train B) is greater than $11.5 \mathrm{psig}$. Condition reset occurs when pressure drops below $\sim 11.0 \mathrm{psig}$. The MCO High-Pressure trip relay contact opens on high pressure. A five-sample average is used to reduce the potential for spurious trips.

\section{MCO Low Flow Purge Trip}

The MCO low purge flow trip monitors the GSHe supply flow and trips if flow is below 1.7 $\mathrm{scfm}$ when required. This flow assures low hydrogen levels during the drying and proof modes. The setpoint is based on equilibrium hydrogen levels below the LFL of 4 percent.

The low flow trip occurs when helium flow, as measured on FIT $1 * 20$ (Train A) or FIT $1 * 21$ (Train B), drops below $1.7 \mathrm{scfm}$. The MCO Low Flow Purge trip relay contact opens on low flow. This condition is reset when purge flow is $>\sim 1.75 \mathrm{scfm}$. For MCO flow signals from FIT $1 * 20$ and FIT $1 * 21$, a 15 -sample average is used.

\section{MCO Low Purge Flow Bypass}

The MCO low purge flow bypass allows for a five-minute period with no flow, which is a process requirement so that a 12 -torr [ 8 torr] vacuum level can be reached. During the vacuum cycle with a minimum helium purge, the lowest vacuum level that can be reached is approximately 50 to 70 torr. The helium flow is stopped to allow the vacuum pump to bring the MCO pressure below the 12-torr parameter limit.. See item 9 (below) for details regarding the 12 torr bypass.

Any time the flow is below the MCO low purge flow trip point, as described above, a fiveminute bypass timer is started. Reset occurs when flow is above the low flow reset point or a manual trip RESET has occurred.

NOTE: For post-trip conditions, there is zero flow indicated as FIT $1 * 20$ and FIT $1 * 21$ are isolated by the ISO \& PURGE trip. The MCO low purge flow bypass is reset to five minutes by the ISO \&PURGE trip signal, which allows for normal flow to be re-established through the $\mathrm{MCO}$ after the trip reset has been initiated.

\section{MCO 12-Torr Purge Bypass}

The 12-torr bypass limit is based on the quantity of hydrogen being maintained below the amount capable of supporting combustion. Once the vacuum pressure is below this value, no helium purge is required.

A trip logic bypass is provided when MCO pressure, as read on PT $1 * 08$ (Train A) and PT $1 * 10$ (Train B), is below 7.5 torr for a continuous period of 10 seconds. Reset (open contact) occurs any time pressure is above 8.0 torr. For MCO pressure signals from PT $1 * 08$ and PT $1 * 10$, a 15sample average is used. Upon return to above 12 torr [ 8 torr], there is a built-in time delay for contract opening of two minutes to account for the SCHe flow meter and flow control component response time. 


\section{Vacuum Limit Timer Trip}

This timer trip limits the time under vacuum, defined as being $<0.24$ psig parameter limit, to eight hours for the initial vacuum cycle and four hours for each subsequent cycle. A four-hour at-pressure period must be performed (thermal reset) between the vacuum cycles. Exceeding the eight-hour or four-hour timers or failure to perform a four-hour thermal reset results in an isolation and purge of the MCO. If during the eight-hour vacuum time, pressure is increased above 0.5 psig, pressure cannot be taken back to vacuum unless the four-hour thermal reset is completed. Once returning to vacuum, the timer limit is set to four hours. This is implemented to protect against cycling between pressure and vacuum that heats the fuel, which invalidates the eight-hour allowance. The four-hour under-vacuum timer is cumulative since times at pressure do not impact the four-hour vacuum limit and stop the vacuum limit timer. Reset occurs only if the entire four-hour thermal reset has occurred without interruption.

Time under vacuum (defined as $<0.5 \mathrm{psig}$ ) is monitored and a trip occurs if the total time exceeds an eight-hour period for the first vacuum cycle and a four-hour period for all subsequent cycles, unless a four-hour thermal reset (continuous pressure above $\sim 0.5 \mathrm{psig}$ ) occurs prior to reaching the timed limit.

The vacuum timer is pre-set to eight hours at the beginning of the 5 DRYING mode. If during the first eight-hour period, pressure is increased above $0.5 \mathrm{psig}$, the timer stops its countdown. Returning to vacuum without first satisfying the four-hour thermal reset initiates a trip. This prevents going back and forth from vacuum to pressure during the eight-hour allowance.

Unlike the previous averaging for PT $1 * 36$ and PT $1 * 37$, a 15 -sample average is used for the $8 / 4 / 4$ timer parameters. This helps to reduce the potential for false $8 / 4 / 4$ trips.

The vacuum timer pre-set is changed from eight hours to four hours once the eight-hour timer has started and a four-hour thermal reset has been completed.

Should an ISO \& PURGE trip be initiated during the mode(s) when the vacuum limit timer is active, the manual reset button actuation positions the vacuum limit timer to require a four-hour thermal reset prior to $\mathrm{MCO}$ pressure going below $0.5 \mathrm{psig}$. Otherwise, an ISO \& PURGE trip occurs.

\section{MCO Pressure Decay Fail Trip}

The pressure decay fail is an indication of a degraded vacuum pump or a substantial leak in the system piping. The parameter limit is based on the transition time from the MCO being above atmosphere ( $>0.5 \mathrm{psig})$ to a vacuum of less than $-11.7 \mathrm{psig}$ ( 155 torr) not exceeding five minutes. A degraded vacuum pump affects the fuel temperature (thermal runaway concerns) by allowing higher than desired steam pressures as the vacuum pump efficiency is reduced. In addition, a degraded vacuum pump allows higher concentrations of hydrogen during vacuum pumping. The detection of a major leak could allow air to be circulated through the fuel, which 
at first would actually help with reaction rates. Continued air ingress could cause fuel heating, particularly if uranium hydrides are present.

A MCO pressure decay fail occurs if pressure drops below $0.5 \mathrm{psig}$ (decreasing value) on PT $1 * 36$ or PT $1 * 37$ for more than five continuous seconds and pressure does not drop below -11.7 psig ( 155 torr) (same field instruments) within five minutes. Once $<-11.7$ psig ( $\sim 155$ torr) is reached, this timer is reset and held until pressure is again above $0.5 \mathrm{psig}$.

\section{MCO Pressure Rise Fail Trip}

The pressure rise fail trip indicates a substantial leak in the system piping. The parameter limit is based on the transition time from the MCO being below -11.1 psig ( $\sim 185$ torr) to achieving above atmosphere ( $>0.5 \mathrm{psig}$ ) conditions in the $\mathrm{MCO}$ within five minutes. The detection of a major leak could allow air to be circulated through the fuel, which at first would help with reaction rates. Continued air ingress could cause fuel heating, particularly if uranium hydrides are present. This condition is reset when MCO pressure is $>0.5$ psig as measured by PT $1 * 36$ and PT $1 * 37$.

4.1.6.4.2 PWC Alarm Setpoints. The PLC also provides a Defense-In-Depth MCO external hydrogen control alarms to the safety-class annunciator for the PWC pre-purge and post-purge. The purges ensures that no air (oxygen) is present in the receiving tanks prior to draining the $\mathrm{MCO}$ bulk water and assures that a purge after draining occurs if the receiving tanks contain high levels of hydrogen. These alarms require operation action outside the scope of the SCIC system.

For PWC flow signals from FIT $1 * 20$ and FIT $1 * 21$, a 15-sample average of no greater than 100 ms per sample is used.

Condition 1: PWC Pre-Purge: A bay PWC low flow alarm is initiated if a minimum flow of 8.4 $\mathrm{scfm}$ is not maintained for greater than 19 minutes during the first 21 minutes after entering the 3 DRAIN mode. The 19-minute timer is reset if flow drops below $8.4 \mathrm{scfm}$ during the 19-minute countdown period. If after 21 minutes the flow requirement has not been meet, an alarm is sent to the SCIC control room annunciator and remains locked in until either a) a continuous 19 minutes of $>8.4 \mathrm{scfm}$ purge is completed, or $b$ ) the mode switch is placed in any other position than 3 DRAIN.

Note: Should manual operator action provide the PWC pre-purge function, this alarm is locked in the annunciator until the mode switch is repositioned.

Condition 2: PWC POST-PURGE: After entering 4 PURGE/FLUSH, there is a delay of 17 minutes for a blowdown of the SCHe and a de-ionized water rinse, then a bay PWC low flow timer is initiated. The PWC low flow alarm will activate if a minimum flow of $8.4 \mathrm{scfm}$ is not maintained for at least 19 minutes before 38 minutes have elapsed since entering the 4 PURGE/FLUSH. The 19-minute timer is reset if flow drops below $8.4 \mathrm{scfm}$ during the 19minute countdown period. If after 21 minutes, from the 17 -minute delay for starting the PWC post-purge timer, the flow requirement has not been met, an alarm is sent to the SCIC control 
room annunciator and remains locked in until the mode switch is placed in any other position than 3 DRAIN.

Time 0: $\quad$ Mode Switch To 4 PURGE/FLUSH

Time 2: $\quad$ two-minute delay for SCHe blowdown

Time 17: 15 -minute delay for -ionized water rinse

Time 19: two-minute delay for MCS and FITs to respond

Time 38: 19 minutes at $>8.4$ scfm flow for post-purge

These safety-significant alarms are sent to the safety-class annunciator to indicate PWC low flow for each bay. These alarms are normally clear (off).

4.1.6.4.3 Annulus Low Level Alarm Setpoint. A low level in the cask annulus is required to alarm if water level in the annulus drops below the level of the fuel. The physical position of the level gauges and attached switch is approximately a foot above the $\mathrm{MCO}$, which is substantially above the fuel level. The LSL alarm is set at $\sim 50 \%$ of the reading of the level indicator, which assures a level alarm well above the level of the fuel.

\subsection{Operations}

Test specifications will be developed to identify factory acceptance, construction acceptance, and pre-operational test procedures.

\subsubsection{Initial Configurations (Pre-startup)}

The SCIC system and related safety-class systems must be operational before an MCO can be connected to the process piping and must remain operational for the duration of the drying process.

Prior to accepting an MCO, the SCIC system must be verified to be in the 1 BYPASS mode. (NOTE: The seismic trips, TW high temperature trips, and PWC seismic trips are always active.) This is accomplished by placing both mode switches in the 1 BYPASS position (HS-6707, HS6708, HS-6709, and HS-6710 Train A and HS-6807, HS-6808, HS-6809, and HS-6810 Train B). Specific alignments and configurations will be identified in the test specifications.

\subsubsection{System Startup}

The SCIC system is generally ready for system operations at all times. In the 1 BYPASS mode, the MCS has full control of all MCO isolation valves, which is necessary to establish the process connectors on the MCO. Once the MCO is connected, the mode switches are moved to the remaining six positions to support MCO fuel heat-up, draining, and drying. The only reason for an actual startup is if the equipment is de-energized due to a loss of power or maintenance. In this situation, no special procedures or steps need to be followed for the system to be ready, except to reset the TW trip, the MCO ISO \& PURGE trip, and the seismic trips. 


\subsubsection{Normal Operations}

The SCIC is a passive system during most of the operational steps. During the Purge/Rinse mode, the SCIC opens the two SCHE long dip tube isolation valves to blow down any collected water in the line. Aside from this function, the SCIC is passive and responds when process parameters reach SCIC trip or alarm setpoints. The only operator functions required during normal operations is to control the position of the mode selector switches, test the annunciator function, and bypass the annulus water level alarm when required. The need for routine surveillance is anticipated to perform instrument value channel checks, and some limited functional tests and calibrations. The scope and frequency of safety surveillances is detailed in the Technical Safety Requirements (HNF-3673).

The purpose of the mode switches is to enable and disable interlocks, provide selected mode status to the PLC for enabling and disabling protection logic, pass all mode position status to the non-safety MCS for process operations, and operate selected SCHe valves to blow down the SCHe long dip tube piping. A table summarizing which trips and interlocks are active during the different modes is found in Table 4-3. Operating procedures will be developed.

\subsubsection{Off-Normal Operations}

If a safety-class event, aside from the TW (annulus) temperature trip, occurs during processing, the SCIC system immediately isolates and purges the MCO. On a high TW (annulus) trip, the SCIC system shuts down the water heater and pump. These actions are fully automatic and require no operator action. For a seismic trip, both TW (annulus) heater and pump shut down, and $\mathrm{MCO}$ isolation and purge occurs.

The system isolates the MCO and starts a helium purge at any time if any of the following occur:

1. A seismic event above the magnitude that affects non-qualified system operation, such as the MCS, piping, and/or equipment.

2. Operator-initiated isolation and purge from the local operator panel or the SCIC system control room annunciation panel purge activation buttons.

3. An incorrect pressure state within the $\mathrm{MCO}$ without an adequate, verified purge rate:

a) The MCO pressure drops below 0.5 psig without an adequate helium purge.

b) The MCO pressure drops below 0.5 psig during the water draining or purge/rinse operation

c) During vacuum processing, the MCO pressure fails to reach -11.7 psig ( $\sim 155$ torr) (from $0.5 \mathrm{psig}$ ) within a preset time period. 


\section{SNF-3091 REV 0}

Table 4-3. Safety-Class Instrumentation and Control Trip, Interlock, and Alarm Summary

\begin{tabular}{|c|c|c|c|c|}
\hline Mode & PLC trips (Note 1) & Non-PLC trips & Interlocks & Alarms \\
\hline 1 BYPASS & None & $\begin{array}{ll}- & \text { Seismic } \\
- & \text { TW high temperature } \\
- & \text { Local and remote ISO \& PURGE buttons } \\
- & \text { PWC pump seismic trip* } \\
\end{array}$ & None & $\begin{array}{ll}- & \text { Bay * purge } \\
- & \text { TW annulus low level } \\
& \text { (Note 2) }\end{array}$ \\
\hline 2 HEATUP & MCO high pressure & $\begin{array}{ll}\text { - } & \text { Seismic } \\
\text { - } & \text { TW high temperature } \\
\text { - } & \text { Local and remote ISO \& PURGE buttons } \\
\text { - } & \text { High bay temperature } \\
\text { - } & \text { PWC pump seismic trip* } \\
\end{array}$ & $\begin{array}{l}\text { PWC-GOV } 1 * 30,1^{*} 03 \text {, VPS- } \\
\text { GOV-1*11, } 1^{*} 17 \text { (drain and } \\
\text { rinse valves) }\end{array}$ & $\begin{array}{ll}- & \text { Bay * purge } \\
- & \text { TW annulus low level }\end{array}$ \\
\hline 3 DRAIN & MCO high and low pressure & $\begin{array}{ll}- & \text { Scismic } \\
- & \text { TW high temperature } \\
- & \text { Local and remote ISO \& PURGE buttons } \\
- & \text { High bay tempcrature } \\
- & \text { PWC pump seismic trip* } \\
\end{array}$ & None & $\begin{array}{ll}- & \text { PWC low flow* } \\
- & \text { Bay* purge } \\
- & \text { TW annulus low level }\end{array}$ \\
\hline $\begin{array}{l}4 \text { PURGE/ } \\
\text { FLUSH }\end{array}$ & MCO high and low pressure & $\begin{array}{ll} & \text { Seismic } \\
\text { - } & \text { TW high temperature } \\
\text { - } & \text { Local and remote ISO \& PURGE buttons } \\
\text { - } & \text { High bay temperature } \\
- & \text { PWC pump seismic trip* } \\
\end{array}$ & Note 3 & $\begin{array}{ll}- & \text { PWC low flow* } \\
- & \text { Bay * purge } \\
& \text { TW annulus low level }\end{array}$ \\
\hline 5 DRYING & $\begin{array}{l}\text { MCO high and low pressure } \\
\text { MCO prepurge } \\
\text { MCO low purge flow } \\
\text { MCO } 12 \text {-torr purge bypass } \\
\text { MCO low purge flow bypass } \\
\text { MCO pressure decay fail } \\
\text { MCO pressure rise fail } \\
\text { MCO } 8 \text {-hr vacuum limit timer } \\
\text { MCO } 4 \text { hr vacuum limit timer }\end{array}$ & $\begin{array}{ll} & \text { Seismic } \\
- & \text { TW high temperaturc } \\
- & \text { Local and remote ISO \& PURGE buttons } \\
- & \text { High bay temperature } \\
- & \text { PWC pump seismic trip* }\end{array}$ & $\begin{array}{l}\text { PWC-GOV } 1 * 30,1 * 03, \text { VPS- } \\
\text { GOV-1*11,1*17 (drain and } \\
\text { rinse valves) }\end{array}$ & $\begin{array}{ll}- & \text { Bay * purge } \\
- & \text { TW anmulus low level }\end{array}$ \\
\hline 6 PROOF & $\begin{array}{l}\text { MCO high and low pressure } \\
\text { MCO prepurge } \\
\text { MCO low purge flow } \\
\text { MCO 12-torr purge bypass } \\
\text { MCO low purge flow bypass } \\
\text { MCO pressure decay fail } \\
\text { MCO pressure rise fail } \\
\end{array}$ & $\begin{array}{ll}- & \text { Seismic } \\
\text { - } & \text { TW high temperature } \\
\text { - } & \text { Local and remote ISO \& PURGE buttons } \\
\text { - } & \text { High bay temperature } \\
\text { - } & \text { PWC pump seismic trip* }\end{array}$ & $\begin{array}{l}\text { PWC-GOV } 1 * 30, I^{* 0} 03, \text { VPS- } \\
\text { GOV-1*11, } 1^{*} 17 \text { (drain and } \\
\text { rinse valves) }\end{array}$ & $\begin{array}{ll}- & \text { Bay * purge } \\
- & \text { TW annulus low level }\end{array}$ \\
\hline $\begin{array}{l}7 \text { PRESSURE } \\
\text { TEST }\end{array}$ & MCO pressure rise fail & $\begin{array}{ll}- & \text { Seismic } \\
\text { - } & \text { TW high temperature } \\
- & \text { Local and remote ISO \& PURGE buttons } \\
- & \text { High bay temperature } \\
\end{array}$ & $\begin{array}{l}\text { VPS-GOV } 1 * 05,1 * 09 \\
\text { PWC-GOV } 1 * 30,1 * 03 \text {, VPS- } \\
\text { GOV- } 1 * 11,1 * 17 \text { (drain and } \\
\text { rinse valves) }\end{array}$ & $\begin{array}{ll}- & \text { Bay * purge } \\
- & \text { TW annulus low level }\end{array}$ \\
\hline
\end{tabular}

*For defense in depth only (not safety class or safety significant)

Notes:1. All PLCs have an associated PLC fault trip built into the PLC logic.

2. TW annulus low level is bypassed by operations when there is no $\mathrm{MCO}$ or when the annulus is drained for shipment.

3. During the PURGE/FLUSH mode the SCHe valves (SCHe-GOV 5*21 and 5*31) on the long process tube side are opened for 2 minutes (deenergized by the SCIC) to blow down any water that may have collected from the drain sequence. 
d) During vacuum processing, the MCO pressure increases above $-11.1 \mathrm{psig}$ ( 185 torr) to above $0.5 \mathrm{psig}$ within a preset time period.

e) The MCO pressure is less than 0.5 psig and the normal process helium flow timer is timed out.

f) The MCO pressure increases above 11.5 psig.

4. The first vacuum processing under $0.5 \mathrm{psig}$ exceeds its eight-hour time limit without returning to above $0.5 \mathrm{psig}$ for a minimum of four hours.

5. Subsequent vacuum processing cycles under 0.5 psig exceeds the four-hour time limit without returning to above $0.5 \mathrm{psig}$ for a minimum of four hours.

6. A process bay high temperature switch trips.

The SCIC system initiates an MCO ISO \& PURGE if the high-temperature switch is tripped (TSHH- $1 * 38$ and TSHH- $1 * 39$ ).

NOTE: In the event of loss of power, the system assumes a safe shutdown mode that isolates and purges the $\mathrm{MCO}$ and de-energizes the TW heater and pump.

Response to alarms in the control room or on the local control panels is as follows:

- For the loss of annulus water, operator action is required to refill the annulus within approximately 12 hours.

- For an $\mathrm{MCO}$ isolation and purge, the operator verifies that the correct action has taken place by monitoring the MCS and by inspecting the process bay, as appropriate. Followup recovery action is initiated following established procedures.

When the conditions causing the shutdown have been identified and corrected, the system is reset from the local operator panels and processing is resumed.

\subsubsection{System Shutdown}

The SCIC system is placed in shutdown by moving the mode selector key switch on the local operator panels to 1 BYPASS. Note that the TW over-temperature trip and seismic trip is still active.

\subsubsection{Safety Management Programs and Administrative Controls}

The safety management programs and administrative controls for this SDD will be integrated into the SNF Project integrated safety management system. 
There are seven SCIC operating mode positions: 1 BYPASS, 2 HEATUP, 3 DRAIN, 4 PURGE/FLUSH, 5 DRYING, 6 PROOF, and 7 PRESSURE TEST. The operator using administrative procedures controls the position of this switch. Surveillance is required and identified in the Technical Safety Requirements (HNF-3673).

\subsection{Testing And Maintenance}

The hardware components of the SCIC system are designed to operate through the design life of the equipment (five years) without regularly scheduled facility shutdowns for maintenance. System maintenance activities are limited to maintenance due to failures. Routine system checks are performed to verify system performance. Standard calibrations are performed annually, or at recommended intervals, during periods without an $\mathrm{MCO}$. Testing of a seismic trip affects all four bays as these signals come from the common $2 / 3$ logic panels.

Additional maintenance activities and procedures may be scheduled if system surveillance, testing, or maintenance identifies additional requirements. All maintenance is performed under controlled procedures using approved (quality assurance-qualified) equipment and materials. The surveillance, testing, and maintenance of the system are achieved at minimum cost and level of support services per DOE Order 6430.1A, General Design Criteria, Section 1300-12.4.10.

\subsubsection{Temporary Configurations}

All replacement and spare parts are fabricated by the same manufacturer and have the same model number as the original or an engineering-approved equivalent. In addition, the quality assurance requirements listed in Table 4-5 must be met:

Table 4-3. Equivalent Parts Quality Assurance Requirements

\begin{tabular}{|l|l|c|}
\hline \multicolumn{1}{|c|}{ Item } & \multicolumn{1}{|c|}{ Safety Function } & Quality Assurance \\
\hline Push buttons, lights, switches, enclosures & Augment automatic shutdown system & NQA-1 \\
\hline Terminal strips & Safety shutdown signal distribution & NQA-1 \\
\hline Relays & Safety shutdown signal distribution & NQA-1 \\
\hline $\begin{array}{l}\text { PLCs, transmitters, process switches, } \\
\text { valves, and components }\end{array}$ & $\begin{array}{l}\text { Provide emergency MCO isolation and } \\
\text { purge }\end{array}$ & NQA-1 \\
\hline
\end{tabular}

Replacement wiring meets the following requirements:

- Connections to pilot lights, push buttons, selector switches, relay sockets, terminal blocks, and others with screw type terminals use AMP PDIG ring tongue terminals crimped to the manufacturer's recommendation. The size is matched to the appropriate stud or screw size. Factory-calibrated crimp tools are used. 
SNF-3091 REV 0

Appendix A

Source Documents 


\section{INDUSTRY STANDARDS AND CODES}

ANSI/ASME NQA-1, 1997, Quality Assurance Requirements for Nuclear Facility Applications, American Society of Mechanical Engineers, New York, New York.

ANSI/ISA-S67.04, 1994, Setpoints for Nuclear Safety-Related Instrumentation, Instrument Society of America, Part 1, Research Triangle Park, North Carolina.

UBC, 1994, Uniform Building Code, International Conference of Building Officials, Whittier, California.

\section{GOVERNMENT DOCUMENTS}

10 CFR 72 Sub Part G, "Licensing Requirements for the Independent Storage of Spent Nuclear Fuel and High-level Radioactive Waste," Code of Federal Regulations, as amended.

DOE Order 6430.1A, 1989, General Design Criteria, U.S. Department of Energy, Washington, D.C.

DOE-STD-1020-94, 1994, Natural Phenomena Hazards Design and Evaluation Criteria for Department of Energy Facilities, DOE Standard 1020-94, U.S. Department of Energy, Washington, D.C.

\section{SPENT NUCLEAR FUEL PROJECT DOCUMENTS}

HNF-1851, 1997, Cold Vacuum Drying Residual Free Water Test Description, Rev. 0, Fluor Daniel Hanford, Inc., Richland, Washington.

HNF-2155, 1998, Multi-Canister Overpack Combustible Gas Management Leak Test Acceptance Criteria, Rev. 0, Fluor Daniel Hanford, Inc., Richland, Washington.

HNF-2356, 1998, Spent Nuclear Fuel Project Cold Vacuum Drying Facility Operations Manual, Rev. 0b, DE\&S Hanford, Inc., Richland, Washington.

HNF-3553, 1999, Annex B - Final Safety Analysis Report for the Cold Vacuum Drying Facility, Rev. 0, Fluor Daniel Hanford, Incorporated, Richland, Washington

HNF-MP-599, 1997, Project Hanford Quality Assurance Program Description, Rev. 1, Fluor Daniel Hanford, Inc., Richland, Washington.

HNF-SD-SNF-DRD-002, 1998, Cold Vacuum Drying Facility Design Requirements, Rev. 4, Fluor Daniel Hanford, Inc., Richland, Washington. 
HNF-SD-SNF-OCD-001, 1998, Spent Nuclear Fuel Project Product Specification, Rev. 1, Fluor Daniel Hanford, Inc., Richland, Washington.

HNF-SD-SNF-SEL-002, 1998, Spent Nuclear Fuel Project Cold Vacuum Drying Facility Safety Equipment List, Rev. 6, Fluor Daniel Hanford, Inc., Richland, Washington.

SNF-3001, 1998, CVDF Data and Calculation Matrix Tracking List, Rev. A, DE\&S Hanford, Inc., Richland, Washington.

WHC-SD-SNF-RPT-010, 1996, Spent Nuclear Fuel Project Operational Description, Rev. 0, Westinghouse Hanford Company, Richland, Washington. 
SNF-3091 REV 0

Appendix B

System Drawings

B-1 
Assembly and wiring of the SCIC system are shown on the following drawings:

H-1-82161, Cold Vacuum Drying Facility Process Equipment Skid P\&ID MCO/Cask Interface, Rev. 2, Fluor Daniel Hanford, Inc., Richland, Washington.

H-1-82162, Cold Vacuum Drying Facility Process Equipment Skid P\&ID Vacuum Pumping System, Rev. 1, Fluor Daniel Hanford, Inc., Richland, Washington.

H-1-82163, Cold Vacuum Drying Facility Process Equipment Skid P\&ID MCO/Temp Water System, Rev. 1, Fluor Daniel Hanford, Inc., Richland, Washington.

H-1-82164, Cold Vacuum Drying Facility Process Water Conditioning P\&ID, Rev.1, Fluor Daniel Hanford, Inc., Richland, Washington.

H-1-82165, Cold Vacuum Drying Facility SCHE System P\&ID, Rev.1, Fluor Daniel Hanford, Inc., Richland, Washington.

H-1-82301, Cold Vacuum Drying Facility SCIC System Instrument Rack Assembly, Rev. TBD, Framatome Technologies, Lynchburg, Virginia.

H-1-82305, Cold Vacuum Drying Facility Seismic System Connection Diagram, Rev. TBD, Framatome Technologies, Lynchburg, Virginia.

The related piping and instrumentation diagrams can be found on the following drawings:

H-1-83766, Cold Vacuum Drying Facility Process System P\&ID, Rev. 2, Numatec Hanford Corporation, Richland, Washington.

H-1-83767, CVDF Vacuum Purge Chilled Water System P\&ID, Rev. 2, Numatec Hanford Corporation, Richland, Washington.

HNF-3673, Cold Vacuum Drying Facility Technical Safety Requirements, Rev. 0, Duke Engineering and Services Hanford, Inc., Richland Washington.

HNF-3553, Final Safety Analysis Report, Rev. 0, Duke Engineering and Services Hanford, Inc., Richland Washington. 
SNF-3091 REV 0

Appendix C

System Procedures

C-1 
SNF-3091 REV 0

Procedures are not yet developed.

C-2 